
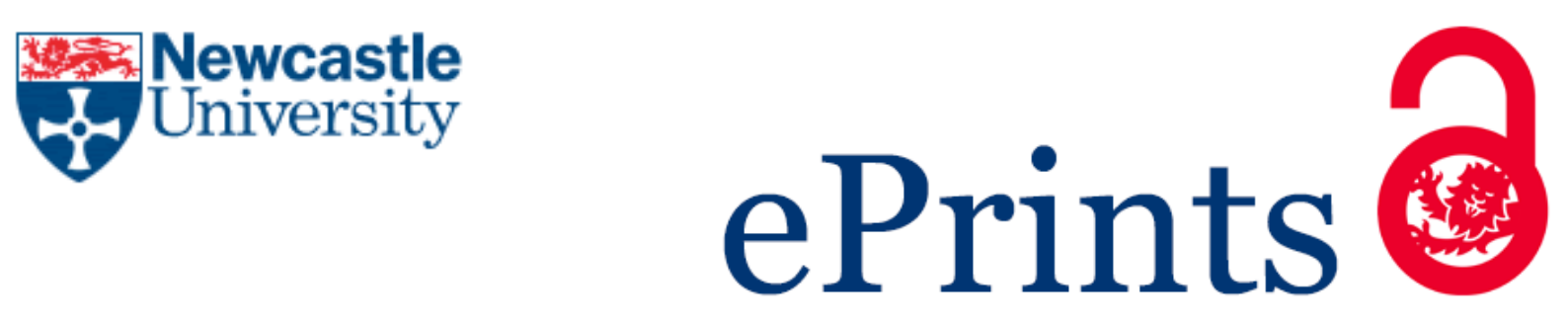

\author{
Kelly H, Kennedy F, Britton H, McGuire G, Law J. \\ Narrowing the "digital divide"-facilitating access to computer technology to \\ enhance the lives of those with aphasia: a feasibility study. \\ Aphasiology 2016, 30(2-3), 133-163.
}

\title{
Copyright:
}

This is an Accepted Manuscript of an article published by Taylor \& Francis in Aphasiology on 21/08/2015, available online: $\underline{\text { http://www.tandfonline.com/10.1080/02687038.2015.1077926 }}$

DOI link to article:

https://doi.org/10.1080/02687038.2015.1077926

Date deposited:

09/03/2017

Embargo release date:

21 August 2016

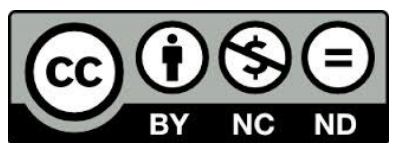

This work is licensed under a

Creative Commons Attribution-NonCommercial-NoDerivatives 4.0 International licence 


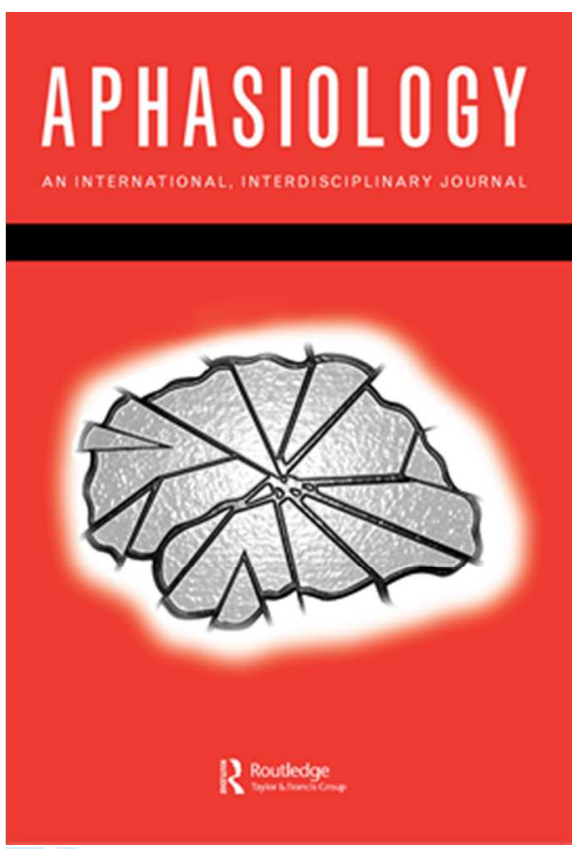

\section{Narrowing the "digital divide" - facilitating access to computer technology to enhance the lives of those with aphasia: a feasibility study}

\begin{tabular}{|r|l|}
\hline Journal: & Aphasiology \\
\hline Manuscript ID: & APH-SI 15-079.R1 \\
\hline Manuscript Type: & Special Issue \\
\hline Date Submitted by the Author: & 19-Jun-2015 \\
\hline Complete List of Authors: & $\begin{array}{l}\text { Kelly, Helen; University College Cork, Speech \& Hearing Sciences; Queen } \\
\text { Margaret University, Speech \& Hearing Sciences } \\
\text { Kennedy, Fiona; University College Cork, Speech \& Hearing Sciences } \\
\text { Britton, Hannah; Queen Margaret University, Speech \& Hearing Sciences } \\
\text { McGuire, Graham; Speakability Edinburgh, } \\
\text { Law, James; Newcastle University, School of Education, Communication } \\
\text { and Language Sciences }\end{array}$ \\
\hline Keywords: & aphasia, technology, access, computer classes, barriers \\
\hline &
\end{tabular}


Title: Narrowing the "digital divide" - facilitating access to computer technology to enhance the lives of those with aphasia: a feasibility study

\title{
Running Title: $\quad$ Accessible ICT for people with aphasia
}

\section{Corresponding Author: Dr. Helen Kelly}

Affiliations: Speech \& Hearing Sciences, School of Clinical Therapies, University College Cork, Ireland, and Queen Margaret University, Edinburgh, Scotland

Correspondence to: Dr. Helen Kelly, Speech \& Hearing Sciences, Brookfield Health Sciences Complex, University College Cork, College Road, Cork, Republic of Ireland. Tel: + 353 (21) 490 1746. Email: helen.kelly@ucc.ie

\section{Ms. Fiona Kennedy \\ Speech \&Hearing Sciences, University College Cork, College Road, Cork, Republic of Ireland}

\section{Ms Hannah Britton \\ Queen Margaret University, Edinburgh, Scotland. Email: hannah.britton@,nhslothian.scot.nhs.uk}

\section{Mr. Graham McGuire}

Chairman, Speakability, Edinburgh, Scotland Tel: +44 (131) 4471372 Email: graham1mcguire@gmail.com

\author{
Professor James Law \\ School of Education, Communication and Language Sciences, King George VI Building, \\ Newcastle University, Queen Victoria Road, Newcastle upon Tyne, NE1 7RU. Email: \\ james.law@ncl.ac.uk
}


This project was supported by the Self Management Fund for Scotland provided by the Scottish Government, administered by Health and Social Care Alliance Scotland (previously Long Term Conditions Alliance Scotland).

Acknowledgements: Special thanks to those participants who took part in this study (pseudo-initials are used throughout). Thank you to SLT students from QMU, Edinburgh who supported participants while on Clinical Placement. We are grateful to Michelle Gardner, Louise Cotton and Christine Johnson who facilitated focus group interviews and Anne-Marie Conway who facilitated "Safe sitting at your Computer" session and provided the information for the relevant booklet. Booklets are freely available to download from http://www.qmu.ac.uk/casl/speakability/default.htm 


\begin{abstract}
Background: Despite advances in technology and the universal accessibility of the Internet, the aptly named "digital divide" still prevents equal access to, and use of, computer technology by people with aphasia. The use of technology has clear potential for improved quality of life in terms of increased methods for communicating as well as the facilitation of self-management however, substantial barriers still pervade.
\end{abstract}

\begin{abstract}
Aims: The aims of this study were to evaluate a bespoke computer training course appropriate for people with aphasia and examine the personal experiences of a small sample of individuals with aphasia following their participation on the course.
\end{abstract}

Methods and Procedures: This feasibility study with mixed-methods evaluation recruited participants with a range of aphasia severity and different experiences in using computers. Participants $(n=17)$ discussed their personal experiences of attending the computer course, gathered through topic guided small focus groups, immediately post-course and follow-up refresher class. A Framework Method approach was considered an appropriate methodological design and data were analysed using thematic analysis. Participants also selfrated their skills in using computers before and following this bespoke computer course $(\mathrm{n}=16)$ and at follow-up $(\mathrm{n}=10)$ which was statistically analysed.

Outcomes and Results: Statistically significant differences were found in the improved selfrated ability of a range of computer skills following course attendance. However, participants who attended a Refresher class (five, nine or 12 months following course completion) reported that without support a number of these skills had notably reduced. Three main themes emerged from the focus group data, (i) Facilitation of Social Engagement technology offered new opportunities to communicate and more independently self-manage day-to-day tasks, (ii) Course Framework - participants reflected on their preferred model of 
delivery of the course, and finally (iii) Overcoming Barriers to Computer Usage - the advantages of bespoke training, and requirements for on-going support were highlighted as essential components of a training course appropriate for people with aphasia.

Conclusions: The personal experiences of this group of people with aphasia highlight the advantages of accessing technology as a way of facilitating increased communication and an enhanced ability to manage their day-to-day lives. Yet, despite these benefits and the necessity for many people with aphasia to learn or re-learn computer skills, finding courses that can accommodate individual needs is problematic. This research highlights the need for bespoke computer training and follow-on support, and highlights the necessary components of such training as identified by this group of people with aphasia. 
Rapidly evolving developments in information and communication technologies (ICT) have resulted in access to the Internet becoming a significant essential in the daily lives of individuals of all ages. With UK Internet users reportedly spending an average of 31 hours per month browsing the Internet on a laptop or desktop device (Ofcom, 2014), the Internet currently permeates almost every aspect of daily life, including employment, entertainment and social activities. Furthermore, half of UK Government services are now online (Koss, Azad, Gum \& Rosenthal, 2013) and even the provision of healthcare information and management/rehabilitation is increasingly utilising technology and software applications for remote management of chronic health conditions (Brandenburg, Worrall, Rodriguez \& Copeland, 2013; Sarasohn-Kahn, 2010). Major advances in ICT offer a range of affordable devices to access the Internet with the most important in the UK reported to be laptop/notebook (47\%) and desktop computer (31\%), followed by more mobile technology such as Smartphone, Tablet and other devices (Ofcom, 2014). While almost half of the UK online population claim to have advanced technology (i.e. Tablet), laptops remain the most popular device in homes, with laptop and desktop online active audience growing to 39.7 million in 2014 (Ofcom, 2014).

The Internet also facilitates new ways of communication, such as email, Skype, and social networking, helping people to stay connected with family, friends and the world around them (Bakardjeva, 2012). One of the most salient aspects of online communication for individuals with disabilities is the potential to 'mask', for example, physical or cognitive impairment, from the forefront of interactions, thereby, facilitating social interactions that may not otherwise be possible offline (Bowker \& Tuffin, 2002; Guo, Bricout \& Huang 2005; Seymour \& Lupton 2004). More specifically, individuals with communication disorders can use non-verbal (e.g. gesture with Skype) and written strategies (e.g. email) to overcome communication breakdowns in spoken communication when using computers as a medium of 
communication, where the off-line element of technology allows time to process incoming information and formulate responses. Computer and Internet usage has been found to enhance both the level and quality of interactions between individuals with disabilities and others thus broadening their communicative network (Bradley \& Poppen, 2003). Furthermore, enlargement of social networks and increased levels of independence and selfdetermination have also been reported among individuals with disabilities using computer technology (Cook et al., 2005; Grimaldi \& Goette, 1999). The psychosocial benefits of providing Internet access to healthy older adults have been widely reported (Koss et al, 2013) and illustrated in a retirement community which highlighted the importance of facilitating access to technology by older adults (White et al, 2002). This randomised controlled trial indicated that following completion of a training programme, participants reported decreased loneliness, substantial increase in social interactions and significant improvement in quality of life.

The original intent of the Internet was that it would be universally accessible (Berners-Lee, 1999), however, despite computers being more readily available, the aptly named "digital divide" still prevents equal access to, and use of, ICT by different sectors of the community (Cooper, 2006). "Participation", according to the World Health Organisation's (WHO) International Classification of Functioning, Disability and Health (ICF), is defined as "involvement in life roles" (WHO, 2001; p.12). However, fully embracing a move to the provision of leisure pursuits, social networking, government services, and healthcare through technology, consequently results in excluding those people who have difficulties using such technology. Therefore, facilitation of this "digital participation" (Brandenburg et al, 2013) is essential. As highlighted by Elman (2001) participation in the digital world is now as important as participation in the physical world. Notwithstanding clear evidence of potential for increased quality of life through the use of ICT, substantial barriers still prevent people 
with disabilities from accessing computers and the Internet, thereby resulting in them being significantly less likely to use the Internet than their non-disabled peers (Zickuhr \& Smith, 2012). Although the term "digital divide" originally referred primarily to physical difficulties impacting accessibility to technology (Warschauer, 2004), barriers clearly reach beyond physical limitations significantly impacting those with cognitive or communication impairments - one population being people with aphasia (Elman, 2001, Seymour \& Lupton, 2004; Simpson, 2009). Due to the multi-modal nature of aphasia deficits, i.e. reduction in the ability to communicate through speaking, understanding, reading and/or writing, using technology remains a significant challenge (Elman, 2001).

The continual advancement of technology results in the consequential need for training courses to equip people in keeping their ICT skills updated. Additionally, despite the perception that Internet use requires only basic digital literacy, $63 \%$ of working-age and $78 \%$ of retired non-Internet users report that they do not possess the necessary skills to use the Internet (Koss et al, 2013). Despite an increase in the use of Internet by the aging population, with the largest proportion of UK users being over 55 years of age (Ofcom, 2014), computer training generally caters for the needs of the younger generation (mainly text instructions) (Egan, Worrall \& Oxenham, 2004) whereas older generations (>50 years) benefit from the provision of multimedia tutorials employing short, simple instructions to reduce working memory demands, incorporation of illustrations to illuminate text instructions, and an increased font size (Akiyama, 2009).

One of the main barriers to rehabilitation through technology for individuals with aphasia is a lack of accessible training and support for both people with aphasia (Finch \& Hill, 2014; McCall, 2012; Parr, 2007) and SLT clinicians (Davis \& Copeland, 2006). Individuals with aphasia often face significant barriers to computer training due, for example, to impaired comprehension of spoken/written verbal commands, difficulty asking questions, and writing 
deficits (Lazar \& Antoniello, 2008; Elman, 2001). Participation in ICT training may also be compromised by often co-occurring cognitive, sensory-motor and psychosocial impairments. Cognitive deficits including impaired short-term memory and recall of verbal information, reduced attention, distractibility, difficulty sequencing steps to complete tasks and decreased problem-solving abilities (Makin, Turpin, Dennis, \& Wardlaw, 2013; Mok et al., 2004) may present difficulties for individuals with aphasia completing computer-based training. Physical impairments such as hemiplegia, hemiparesis, or limb apraxia may cause additional difficulties when using a standardised keyboard and mouse (Egan et al, 2004). Furthermore, the psychosocial effects of aphasia may result in social access barriers for individuals with aphasia who are considering enrolment on a computer training course given their reduced social network compared to the general population (Hilari \& Northcott, 2006; Hilari, 2011; Davidson, Howe, Worrall, Hickson \& Togher, 2008; Cruice, Worrall \& Hickson, 2006) and limited participation in leisure activities compared to their healthy peers (Cruice et al, 2006) or people without aphasia post-stroke (Hilari, 2011).

Computer training courses and self-directed learning textbooks remain largely inaccessible for individuals with aphasia (Egan et al., 2004). In addition, the environment in which computer classes are typically held, such as large public locations comprising people of varying ages and abilities, can discourage people with disabilities from attending, where the pressure to participate in a non-disabled environment may result in feelings of failure, intimidation and frustration (Obrenovic, Abascal \& Starcevic, 2007). Furthermore, such classes are typically unable to facilitate the complex needs of individuals with aphasia, for example, auditory comprehension impairments, difficulties asking questions and a lack of one-to-one tutoring. Despite the potential benefits of bespoke training programmes (White et al, 2002), it appears that very little study has been undertaken to develop and evaluate courses that are accessible for this population. Egan and colleagues (2004) developed an Internet 
training package accessible for people with aphasia, with outcomes evaluated through Internet skills assessment and questionnaire. Significant differences between pre-course and post-course abilities were found following training completion. Results indicated that people with aphasia were successfully able to learn how to use the Internet with the assistance of one-to-one teaching and materials specifically designed for their needs.

The psychosocial benefits of engaging with ICT (Bradley \& Poppen, 2003; White et al, 2002) suggests potential to reduce negative psychosocial and interpersonal changes often experienced by people with aphasia, for example, feelings of social isolation, frustration, anxiety, stigma, vulnerability and helplessness (Brumfitt, 2006; Nyström, 2006; Parr, 2001). However, given the plethora of challenges that can create barriers for people with aphasia taking opportunities to enhance their lives through the use of technology, it is important to ascertain their perspective and examine their personal experiences in engaging in a bespoke training course developed to reduce such access barriers. The aims of this current investigation were (i) to evaluate a bespoke computer training programme for people with aphasia, and (ii) to examine the perceived functional impact of learning computer skills on their daily lives.

\section{Methods}

This feasibility study with mixed-methods evaluation was developed collaboratively between Queen Margaret University (QMU), Edinburgh and Speakability (a user-led charity for people with aphasia), and was approved by QMU ethics committee. Participants were recruited through flyers and face-to-face discussions with members of stroke charities. In order to examine the experiences of participants with a wide range of communication impairments and computer experience, a purposive sampling strategy was employed; 
participation criteria included (i) presentation with post-stroke aphasia, and (ii) own (or have access to) a laptop or desktop computer.

\section{Participants}

Twenty one participants were recruited to the courses and were permitted to attend even if they did not wish to provide research data. Seventeen of these participants ( 3 female, 14 male - age range 40:2-80:11) provided quantitative and qualitative data for this study. All participants presented with post-stroke communication difficulties, primarily aphasia, apart from one participant who presented with aphasia but whose medical diagnosis was unknown prior to commencement of the course. Time post-onset ranged from six months to 12 years. Table 1 highlights the range and variation in the presentation of participants' aphasia and cognition according to performance on the Comprehensive Aphasia Therapy (CAT) (Swinburn, Porter \& Howard, 2004).

[Table 1 around here]

As Table 1 indicates participants had a range of pre-stroke computer experience; three participants had never previously used computers. Of those computer-experienced participants, computer usage ranged from on average $<1$ weekly to many times daily; for most people this reduced considerably following their stroke with six of these participants unable to use their computer post-stroke.

Attendance at all classes was very high with 100\% attendance for 16 of the 17 participants; one person missed one class due to illness. One participant (UT) had originally attended three classes of the weekly course but withdrew due to ill-health; however he later attended $100 \%$ of the intensive course when his health improved (see Figure 1 for participation process). Twelve participants attended one Refresher class, five, nine, or 12 months following course 
completion with participants providing quantitative $(n=10)$ and/or qualitative $(n=11)$ research data.

\section{Intervention}

The course comprised a number of different components to reduce potential participation barriers and ensure participants would be supported in the development of their computer skills, namely an Orientation Seminar, Computer Class and Refresher Class.

\section{Orientation Seminar}

Being the first time that many participants had considered engaging in formal learning following their stroke, an essential component of the recruitment process was attendance at an Orientation seminar at QMU (where the courses took place). This served to reduce anxiety and concerns about the course itself and to become familiar and comfortable within the University environment. It also provided participants and family the opportunity to meet course facilitators and learn about the course, giving them context for discussions at home. In addition, potential to overcome barriers caused by physical and communication difficulties was illustrated through demonstrating a range of adaptive equipment (e.g. trackerball mouse and screen reader software).

Participants who decided to attend the course completed an information sheet providing details of their computer experience and abilities, and allowed them to indicate topics they wished to learn - this information fed directly into the development of the course content. In order to determine individual support requirements, communication profiles were evaluated using the CAT (Swinburn et al, 2004), and to meet any physical needs, potential benefits of using adaptive equipment were considered through discussion and trialling of equipment. This was further examined during the first class "Safe sitting at your computer" where 
participants were facilitated in finding the most comfortable seating positions by staff trained in computer ergonomics.

\section{Computer classes}

The 3-hour classes (with refreshment breaks) aimed to develop proficiency in computer use by providing a flexible framework that gave people the opportunity to learn or re-learn basic ICT skills at their own pace (Table 2), as well as focusing on individual interests. The majority of participants owned or had access to desktop computers, therefore the course focussed on this platform rather than more advanced technology such as iPads. In saying that, two participants with laptops, and one who newly acquired an iPad during the course, were encouraged to use them during the classes and materials were individually tailored as required.

\section{[Table 2 around here]}

Two course models were offered which were aligned with timings for SLT student clinical placements - eight weekly classes for eight weeks, or more intensive, eight classes over three weeks - each class comprising a maximum of eight people with aphasia. This allowed exploration of the feasibility of providing different levels of training intensity from the perspective of the participants.

The classes and all materials were developed and delivered by a qualified Speech and Language Therapist (HK). The content was determined through examination of community/public computer classes and importantly topics highlighted by participants during the Orientation Seminar. Most popular topics were provided for the group as a whole, for example, getting information from the Internet, replying to emails (See Table 2). Where participants identified individual topic areas (e.g., inserting document hyperlinks or using 
Skype and Facebook), these were taught on an individual basis. The presentation of receptive and expressive aphasia experienced by the participants (see Table 1) was taken into consideration, in particular, when teaching new terminology and skills. Teaching methods included an introduction to and demonstration of skills using PowerPoint presentations and aphasia-accessible materials. Participants were provided with a booklet for each topic and home-practice tasks, for example, replying to an email from the tutor before the next class. The booklets, based on recommendations by Egan et al (2004), employed screenshots and simplified phrases to guide participants through targeted tasks.

Each participant received 1:1/2:1 support ensuring accessibility of the course through explaining, instructing, facilitating and further adapting course materials to meet individual participant needs, for example, larger text. This element of support was provided by SLT students forming part of their clinical placement. These students had theoretical knowledge about aphasia and were closely overseen by the tutor and supported by indepth discussions about their particular participants at the end of each class. Such level of support ensured the prompt identification and resolution of difficulties encountered by participants. In addition, training focussed on each participant's personal goals thereby aiming to have a positive impact on their daily lives. Personal goals identified by participants included learning how to: use Facebook; Skype relatives living abroad; insert 'hyperlinks' within documents; order grocery shopping online; review online sports results; and use audiobooks. Participants were interviewed individually midway through the course to ascertain their progress and enjoyment of the classes, for example, topics found useful, challenges encountered, identification of further adaptations to facilitate better engagement and learning, and discussion around personal goals for the remainder of the course. 


\section{Refresher Classes}

Following completion of the courses, residual funding allowed the provision of a refresher class for those participants who attended one of the computer courses. Therefore, all participants were invited to attend one Refresher class held at five, nine or 12 months following the course. Refresher classes allowed participants to further practice computer skills and resolve any difficulties experienced since course completion. Participants also provided follow-up data in small focus groups, reflecting on the long-term usefulness of the course and any impact it may have had on their lives.

\section{Data Collection and Analysis}

A mixed-methods approach, employing self-rating scales and focus group discussions facilitated exploration of perceived skill-change, level of computer use, personal experience of the course and, if learning how to use technology had had an impact on participant quality of life.

\section{Self-rated computer usage and computer skills}

Self-rated reporting of computer usage and skills was gathered before and immediately following the course, and during the Refresher classes using an aphasia-accessible rating scale. Participants indicated their average weekly computer usage (Table 1) and how easy or difficult ("impossible" to "no problem") they found a range of tasks, for example," go to a website", "get information from the Internet", "reply to an email" (Tables 3 and 4). Data was analysed using Wilcoxon Signed Ranks Test. 
Personal experiences of the course

In order to gain insight into their experience of the course, all participants were invited to attend focus group discussions, immediately following each course and refresher class (see Figure 1). Given the limited time, the use of focus groups facilitated the capture of a wide range of participant opinions (Kirk \& Miller, 1986). Topic guides (see Appendix) enabled the examination of pre-determined themes related to the structure and impact of the course as well as providing the opportunity to discuss other areas of interest to the group. Focus groups were facilitated by individuals not involved in the development or delivery of the course, apart from one facilitator (MG) who facilitated a group of people she had not been involved with. Three of the facilitators were SLTs and the fourth, an Audiologist; all experienced in working with adults with acquired communication impairments. In order to ensure comprehension and facilitate discussion, facilitators used supportive conversation techniques, such as rephrasing questions or clarifying with open or closed questions, provided pen and paper, and ensured that each person in the group could contribute to the discussions. This format also enabled participants with limited expressive language to offer opinions by indicting agreement or disagreement with other individual's perspectives which would not have been possible without the interaction of the group. Multiple focus groups provided a more representative sample to examine patterns and disparities in participant opinions (Krueger \& Casey, 2000).

A Framework Method was considered an appropriate methodological approach for this study combining both deductive (i.e. pre-established Themes, devised to address research aims) and inductive (themes generated from data) data (Gale et al, 2013; Smith \& Firth, 2011; Pope, Ziebland \& Mays, 2000). Pope et al (2000) identified the following five main stages of data analysis in the framework approach: Familiarisation with the raw data to identify key ideas and recurrent themes, and to identify a thematic framework for detailed examination; 
application of the thematic framework through allocating codes to transcripts supported by text descriptors (Indexing); Charting by rearranging the data according to related thematic framework, forming a chart per key theme, and Mapping and Interpretation through using the charts to identify associations between deductive and inductive themes to provide explanations for the findings. The Framework Method has been used successfully with a number of studies that analysed aphasia-related qualitative data (Law et al, 2010; Parr, 2007; 2001; Wade, Mortley \& Enderby, 2003).

Processes were established to ensure rigour was upheld throughout the data collection and analysis process. Focus groups were audio recorded and verbatim orthographic transcription was carried out in full by $\mathrm{HB}$ and independently checked by FK and $\mathrm{HK}$ who re-listened to the audio files and read the transcribed data. As author HK developed and facilitated the computer course, and in order to maintain transparent integrity HB (student tutor for one course) and FK (not involved in any aspect of the research) also independently analysed the data. The transcripts were coded independently using an agreed coding system by HB (NVIVO software) and FK (paper-based). FK and HK independently categorised the coded data within an agreed framework and held discussions around what constituted codes, subcategories and categories. Any discrepancies were discussed to consensus.

\section{Results}

Self-rated computer usage

Data for pre-and post-course level of computer usage was available for 17 participants (Table 1). Before the course commenced nine participants reported having 'never' used computers post-stroke. Following the course, seven of these participants reported using ICT on a weekly basis while two people used it daily. Three people reported using ICT less than once a week on average increasing post-course to between 1-2 times per week for one person and 3-5 for 
the others. Prior to the course five participants reported using computers either daily or many times daily; this level of usage was maintained following the course. Long-term maintenance of computer usage $(n=10)$ was examined following the Refresher classes. Three participants maintained daily computer usage with three others increasing their usage to daily. One participant reduced usage from daily to 3-5 times per week and the other two participants maintained 1-5 times weekly. Unfortunately, one participant's computer became damaged so was unable to practice his skills following the course.

\section{Self-rated computer skills}

Self-rated skills on a range of computer tasks were reported by 16 participants before and following the course and analysed using Wilcoxon Signed Ranks Test. Table 3 presents the percentage in self-rating scores for each area of ability. Statistically significant improvement in self-reported skills from baseline to post-course were found for 'turning on/off computer' $(\mathrm{z}=-2.539, \mathrm{p}<0.05)$; 'connecting to the Internet' $(\mathrm{z}=-2.699, \mathrm{p}<0.01)$; 'going to a website' $(\mathrm{z}=-$ $2.762, \mathrm{p}<0.01)$; 'getting information from the Internet' $(\mathrm{z}=-3.344, \mathrm{p}<0.01)$; 'using favourites' $(\mathrm{z}=-2.454, \mathrm{p}<0.05) ; \quad$ 'connecting to email' $\quad(\mathrm{z}=-2.689, \mathrm{p}<0.01)$; 'reading email' $(\mathrm{z}=-$ $2.223, \mathrm{p}<0.05)$; 'reply to emails' $(\mathrm{z}=-2.594, \mathrm{p}<0.01)$. No statistical difference was found in 'printing a page' $(\mathrm{p}>0.05)$ which would be expected as it was not included in the course due to technical practicalities. No significant difference was found in 'use online social media' $(p>0.05)$ however, this was only of interest to four people across the courses, three of whom continue to actively use Facebook. Self-rated long-term maintenance of computer skills reported at the Refresher classes $(n=10)$ revealed maintained ability to carry out a range of computer tasks since the end of the computer classes (Table 4). However, a number of skills were deemed more difficult to carry out, in particular, 'reading email' $(\mathrm{z}=-1.913, \mathrm{p}=0.056)$ and reaching significance 'reply to emails' $(\mathrm{z}=-2.041, \mathrm{p}<0.05)$, 'getting information from the Internet' $(\mathrm{z}=-2.043, \mathrm{p}<0.05)$ with $4 / 10$ people finding the task now very difficult/impossible 
or no longer use, and 'using favourites' $(\mathrm{z}=-2.328, \mathrm{p}<0.05)$ (no longer used by $50 \%$ participants). No statistical differences were found related to the other topic areas $(\mathrm{p}>0.05)$.

[Table 3 and Table 4 around here]

\section{Participant personal experiences of the course}

In total 17 participants spoke about their personal experiences of participating in the computer training in the focus groups. While topic guided questions prompted information from pre-established themes, i.e. (i) 'Facilitation of social engagement' and (ii) 'Course framework', the initial open coding approach (to ensure important aspects of the data were not missed) resulted in a third overarching theme (iii) 'Overcoming barriers to technology'.

The desire to learn how to engage with technology in a meaningful way was expressed by all participants who completed the course, irrespective of age, severity of aphasia or previous computer experience. They discussed at length the advantages of using ICT, describing it as a source of information, providing enhanced opportunities to communicate and engage in activities more independently. In addition, participants described tools that helped them overcome barriers to accessing technology-based resources and computer training specifically. Participants articulated in detail the skills they had acquired and/or re-learned and the consequential new opportunities in terms of communication, self-management and overall enhanced quality of life following the computer training. The Refresher classes were referred to by participants as a 'reminder' day where they reported practicing some skills and relearning those that were forgotten e.g. online grocery shopping. These reflections by participants are discussed in relation to the themes and categories that emerged from the data. In addition, Figures 2-4 provide a visual representation of the Framework Matrices related to each theme with examples of categories and codes supported by a range of verbatim quotations from participants. Verbatim quotations identify focus group origin (FG) and 
timeline i.e. immediately following the course (PC) or refresher class (PR), for example, FG4PC relates to a comment made by a participant in focus group 4 , following the course, whereas FG1PR relates to focus group 1, following the refresher class.

\section{Theme 1: Facilitation of social engagement}

Participants deliberated about how attending the computer course had opened up new opportunities to access the same communication, information and leisure opportunities enjoyed by the general population. Specifically, new opportunities to communicate (category 1) and self-manage (category 2) were the main topics discussed (see Figure 2).

\section{New opportunities to communicate}

Attendance at this training course increased the range of technology participants now use when communicating. In particular, many people reported how technology helped them overcome some of the barriers they faced when communicating verbally, for example, TN described the benefits of using the computer compared to telephone correspondence "cos' $I$ can't speak to people on the phone.. cos' they don't understand me...you know.. but when I'm doing it.. on text. it's easier" (FG4PC). Using written rather than spoken communication reportedly helped maximise many participants' capacity for effective communication and enhanced the quality of interactions, making communication easier as discussed by the majority of participants.

The range of communication platforms participants learnt (or relearnt) on the course were discussed and preferred interfaces to connect with family and friends, such as Skype and Facebook were deliberated. Participants highlighted that having the necessary skills to use technology increased the amount of contact they had with people. A number of participants 
learnt how to use Skype to keep in contact with family and friends. $\mathrm{BH}$, for example, found it particularly difficult to speak to family living abroad by telephone so his personal goal was to learn how to use Skype, to converse with his son noting that it was now "a lot easier" to keep in contact with family as both communicators could use non-verbal and written strategies to overcome communication breakdowns maximising communicative effectiveness. Four participants on the course learnt how to use Facebook; three of which still actively use it. One of the main attractions for participants was that it doesn't require much text, photos could be uploaded to share life events, and arrangements for social occasions could be made. To some degree this helped participants mask their disability. TP, for example, has severe expressive aphasia with apraxia of speech but used Facebook to link with people arranging a school reunion which he then attended. Email in particular proved a popular method of communication for all participants, in their communication with family and friends living both at home and abroad and made staying in contact with people more manageable as reported by $D R$, “it's much easier.... and I've.. established an e-mail relationship with.. quite a number of the people.. from school.. we get in touch regularly now by e-mail...and it's a great help" $(F G 2 P C)$. It also made disseminating information easier such as organising committee activities and meetings or in organising holiday arrangements.

\section{[Figure 2 around here]}

\section{Facilitation of self-management}

Another area of importance highlighted by all participants was how technology now facilitated their ability to self-manage their day-to-day lives (Figure 2). Participants reflected on positive changes in their independence and how focusing on personal goals during the classes empowered them to conduct activities of daily living more independently. This included aspects related to the ergonomic use of computers, "so uh.. you know even setting.. 
setting the desk.. and how to.. how to..s- you know what height y-you should be and so on" (BH-FG3PC). Participants' personal goals illustrated the diverse desires of individuals with aphasia and how the use of technology contributes to meeting these needs, fostering more independent and meaningful living. DR reported that she required her computer to help with correspondence, “because I couldn't write letters without my computers.... and I couldn't.. find out the things I want to find about.. and I.. it's.. such a great help"'(FG3PR). Whereas TN had forgotten how to download music following his stroke but found the course "very helpful cos'.. what I wanted to do was download my CDs and everything... and they've shown me how to do it...I used to do all the before.. but I just forgot how to do it"(FG4PC). A number of participants who retained basic computer skills following their stroke learned more advanced tasks pertinent to their social participation. For example, EI, learned how to insert hyperlinks into documents during the course which gave him more independence in organising paperwork related to Cubs - "if I press a button.. I would find.. out.. mine was it's the Cub.. I press that Cub.. I find out where he stays... and more information about him"(FG4PR). Another participant, QN learnt how to organise electronic documents into folders and reported "I am now more organised than I have been for the last 15 years" $(F G 1 P C)$.

A number of people reflected on how learning to use software enabled them to overcome some of the barriers associated with their communication deficits. Screen-reader software was particularly useful to a number of participants who would otherwise not be able to access information on the computer. One participant explained that "it takes me an $h-.$. a hour and a half to read.. one.. page hhh um.. but this in $u$ h $i$ - $i$ - if it will speak. it will read it for $m e "(Q N-F G 2 P R)$. An excerpt from EI's discussion also illustrates how such software reduces reliance on others, promoting independence and self-management: "well it.. it helps me.. fo- this thing here.. I couldn't.. sit and read that ...um but what.. you... on the course...... 
just type it in and listen to it uh.....before.. I was doing.. using the computer.. I was.. um jumping in the car and going to my Mum and Dad's.....it doesnae make sense to me.... and they read it and tel- tell me what it actually means.... but now.. with the computer and that .. typing it in and listen to it.. it just about get making sense" (FG4PR).

The ability to access the Internet in particular was reported by all participants as having a significant positive impact on their overall quality of life. It allowed them to access the same information as the general population as explained by $\mathrm{CN}$ - "one of th-.. one of the lovely things I suppose of the computer business is that... like normally uh at home you'd have a question..you've gotta wait another day.. you know or two days.. or weeks.. until I see someone about it...but the lovely thing is I've got loads of questions that means I can get the old computer.. and then I get the answer back...... that's beautiful that"(FG4PC). Participants commented on the fact that they now use the Internet to independently carry out activities of daily living with online shopping and banking being popular resources for some participants. Others valued the fact that the Internet gave them instant access to resources such as audiobooks, allowing people with aphasia to access the same reading material as the general population "I've got that Talkability thing...I-.. you go to a book and it will speak.. and tell you every word that's in it.... cos' it- it's handy because.. my stroke.. I- I couldnae write.. or I couldn't do reading... and this is very handy it's.. you know" (TN-FG4PC).

The introduction to online media, such as online radio and television, during the training was of great interest to many participants. CX and UT reflected on the benefits of being able to listen and re-listen/replay programmes which helped them overcome difficulties with live media.

\footnotetext{
CX: yes.. just it's easy.. easy way to get the news and.. the weather.. and ((laughs)) and then check the e-mails
} 
UT: the cr- the cricket ((laughs))

CX: oh cricket ((laughs)) the cricket result.. yeh.. oh yes.. yes and then I find.. um... on the radio.. I can find.. what I want to.. um .. if.. if I.. miss... I can then go down the thing and get that one on again..." (FG1PR)

\section{Theme 2: Course framework}

The framework of this training programme allowed individuals to learn or re-learn basic and/or more advanced computer skills, depending upon computer experience. This approach ensured that individual interests of participants were targeted where possible. This flexible framework also allowed participants choose which model of course delivery they wished to attend, i.e. weekly or more intensive classes. This theme facilitated reflection on the "best" model of providing computer training to people with aphasia. The data provided insight into two areas, specifically "computer experience" (category 1) and "course model of delivery" (category 2) (Figure 3).

\section{Computer Experience}

To maximise accessibility for all participants, classes covered a range of skills from the basic use of computers to more advanced activities, thus ensuring the training needs of participants who had never used computers before or those who had forgotten how to use computers poststroke were targeted. It was evident that most previously experienced participants had forgotten a range of computer skills, with some finding even the most basic tasks difficult post-stroke, even if they had worked extensively with computers as part of their pre-stroke employment. Three participants had never used a computer before, and in fact one person (HJ) stated that he had never even 'seen' a computer before - this assertion was supported 
through observation of $\mathrm{HJ}$, for example, lifting the mouse and trying to operate it by trailing it across the monitor on the first day of the course. The other participants had a range of previous computer experience, from basic skills for example as CX termed 'secretarial' skills to others having used ICT skills as part of their employment, or in the case of TM and HE working in the computer industry itself. As expressed by $\mathrm{CN}$, computer knowledge and skills of participants with previous computer experience, were mostly forgotten post-stroke " $I$ used.. when I was a Manager I mean I used th-.. the computer.. and I did.. most of the work I did used that.... and then with the stroke.. I couldn't work it.. and then.. I tried.. again and I just gave up...I was too confused.. I couldn't work it anymore” (FG4PC). There were initial concerns about mixing people with such a wide range of computer experience and while a few participants indicated that it might be useful to have a beginners and more advanced group, the majority of participants reported benefiting from reviewing the basic skills and those participants who were more advanced worked on their more advanced tasks individually with their allocated student for support.

[Figure 3 around here]

\section{Course model of delivery}

Participants were asked to reflect on the frequency and duration of the course and the usefulness of the follow-up Refresher class. Interestingly, all participants who attended the more intensive programme unanimously preferred this model of delivery. Participants explained that this format was advantageous as it was easier to remember their learnt skills from one class to the next. $\mathrm{CN}$ further highlighted that if the course "...had been like you know ((bangs table)) Monday Tuesday Wednesday .. I think it would have been too much". He explained that it was beneficial that the three days were spread out over the week (Monday/Wednesday/Friday), “...but.. $i$ - it helped for me that o-on the Monday.. I'm s- still 
thinking..um...... I'm thinking about things.. so by the Wednesday I'm ready t-to learn more...so it's good.. it gives me twenty-four hours t-to think" (FG4PC). When the group was asked if they would have preferred to attend the course delivered one day per week, all participants in that group responded "no". In contrast, participants who attended the weekly programme did not discuss this aspect of the course during their focus groups.

The majority of participants felt that the eight weeks training was insufficient time for them to learn/ re-learn their targeted skills - "I- I don't think we.. I think you didnae get long enough" (HJ-FG4PC); "too short I think" (TN-FG4PC) whereas a small number were happy with the course length. When asked if they would like the course to be longer participants responded "aye" and some participants asked if other such courses would be running in the future. The Refresher classes were considered to be useful by many participants in helping them practice skills that they had learnt during the computer classes which they had by then forgotten, with some participants calling them 'reminder' classes, highlighting the fact that some participants had forgotten how to carry out some tasks, such as, online grocery shopping, adding email attachments, and creating/accessing website favourites. A number of participants commented that attending these 'reminder' classes also motivated them to continue using their computers and refer to their course booklets.

\section{Theme 3: Overcoming barriers to computer usage/training}

All participants identified several factors which they highlighted as 'crucial' elements to their successful engagement in the training programme. Most participants reported that it would not have been possible to reach their levels of independence using computers without such assistance, namely, "bespoke training" (category 1) and "on-going support" (category 2) (Figure 4). 


\section{Bespoke training}

The importance of the "bespoke" aspect of the training was considered by all participants to have made the course accessible to them. While participants agreed that small class size was an important feature of the course, all participants highlighted two major components which they considered to be essential elements required to facilitate their learning, namely, the specially designed materials (adapted for individual needs) and the participant-tutor ratio i.e. 1:1/2:1 support. The importance of individually tailored booklets was emphasised throughout discussions and considered by all as "hand-outs .... absolutely essential" (QN-FG1PC) during the classes themselves as well as practising at home between classes - "th-the hand-outs.. $v$ very useful.....uh.. you could always look back (BH-FG3PC). Although CX commented that his home computer used older software than the course computers and different screenshots affected how easily he could identify the correct icons in carrying out tasks, with 1:1 tutoring this problem was identified early and booklets were adapted accordingly.

While aphasia-accessible booklets were considered essential, participants unanimously indicated that an equally fundamental aspect of the course was the small tutor to participant ratio. In fact, a number of participants indicated that without this they would not have continued with the course as discussed by $\mathrm{CN}$ and $\mathrm{TN}$ :

CN: I think if.. if it.. if I didn't have someone..w- with me...who's there listening and.. showing me how to do this.. I think I wouldn't have.. th- that.. after that first day I would have shoot and gone

TN: $\quad$ I would have been the same (FG4PC)

[Figure 4 around here] 
Participants reflected on how they could ask tutors anything “aye because you've got a oneto-one.. you can ask them anything"(TN-FG1PR) and having such support gave them confidence in asking for clarification as required to aid understanding "you can ask two or three times.. because I do-don't understand certain things.. but it's all there to say it again" (CX-FG1PR).

On-going support

This short training course provided many participants with basic computer skills necessary for future learning - "only just a stepping stone" (TN-FG1PR). EI reflected "it's good.. it gets you up and started anyway gets you started and gets you keen. This course here was good...basic...I would like to go a bit further" (FG4PR). QN highlighted difficulties for people with aphasia independently learning how to use technology stating “....teaching yourself.. particularly in our situation is one of the real difficulties because.. at least from my point of view.. because my brain doesn't doesn't work properly...so if I'm trying to work out uh..to do something new.. it's really extremely difficult" (FG1PC).

During the follow-up focus groups, many participants indicated that while they continued to use their computers, they highlighted a requirement for on-going post-course follow-up support, with most identifying family or friends for such assistance. Where this support was lacking, newly acquired skills could not be practiced and therefore forgotten. A few participants tried to access support outwith their family/friends network however, it was clear that essential elements required by people with aphasia are not readily available elsewhere. TN explained that his publicly available computer course had just one tutor responsible for the learning needs of the full class which negatively impacted his learning:

"that's what I'm finding now.. if I'm not sure of something.. and I've got to ask the boy..by the time he comes to me.. the class has finished........ if you've got a problem 
with something on the computer...the boy I've got.. he doesn't show you.. he does it himself...you know.. he doesn't take time to show you.. it's too quick...far too quick..you know. you learn nothing.. you know..you come out the class and you're thinking what have I done today..you've done nothing.. you know..and you've got to try and keep up with it.. that's hard" (FG1PR)

Others such as QN had paid for one-to-one tutorials with success dependent upon whether tutors understood the communication and cognitive difficulties that impact the learning of this population. QN stated the "right sort of person...you know that what yo- your problems are.. er.. which is not.. not easy.. they might tell you quite a lot of.. things.. which you then forget.. because of th- th- of the um.. stroke" as they did not understand his communication/cognitive difficulties. However, he noted "but the really good people.. that do exactly the same sort of thing as you people did.. um with th-things that you can.. look at easily.. and keep it.. um.. and that's been very helpful" (FG2PC).

\section{Discussion}

The aims of this mixed-methods feasibility study were to evaluate a bespoke computer training course that could be easily accessed by people irrespective of severity of aphasia or computer experience, and to explore the personal experiences of participants in order to examine any perceived functional impact of learning computer skills on their daily lives. Overall, participants rated their newly learnt or re-learnt computer skills more favourably following the course, reaching statistical significance for most tasks, similar to participants in Egan and colleagues' (2004) study. However, some areas were noted to decline at follow-up. Importantly, small focus groups gave participants the opportunity to describe their personal 
experiences of the course. Three overarching themes emerged from the data: facilitating social engagement, course framework, and overcoming barriers to technology.

Participants described how learning/re-learning ICT skills and expanding their knowledge of technological resources, for example, Skype, email and social media, offered them more opportunities to communicate with family and friends. Many participants advocated off-line technology such as email and Facebook which allowed them overcome communication difficulties, as reported in the literature (Guo et al 2005: Seymour \& Lupton 2004), with increased communication opportunities potentially reducing social isolation (van de SandtKoenderman, 2011). In addition, participants reflected on various ways technology enhanced their autonomy in functional tasks, for instance, learning how to use the Internet facilitated independence in online shopping and banking, and facilitated access to the same information enjoyed by the general public. Participants highlighted how being able to employ resources from the Internet allowed them overcome post-stroke reading difficulties for example, independently "read" books using screen reader applications or listening to audiobooks. Therefore a key finding from this study highlights the importance of technology in facilitating engagement in 'meaningful activities' which is identified in the literature as an important aspect of living successfully with aphasia (Grohn, Worrall, Simmons-Mackie \& Hudson, 2014; Brown, Worrall, Davidson \& Howe, 2012). The literature highlights that while many expressing a desire for increased social activities in their lives, the communication difficulties that people with aphasia experience results in them performing less social activities than healthy older adults (Cruice et al, 2006) and post-stroke individuals without aphasia (Hilari, 2011). The impact of this results in people with aphasia becoming less socially engaged and often experiencing social isolation and exclusion (Parr, 2007; Sarno, 1993). Consistent with the literature (Grohn et al. 2014; Hilari 2011), findings from this study highlight the significance of engagement in social and leisure activities as an 
important means of feeling connected with family and friends, living more independently, empowering increased participation in society, and improvement in overall quality of life.

In order to inform future training, participants were requested to reflect on the course framework in terms of the mix of computer experience, the frequency and duration of classes and the usefulness of the follow-up Refresher class. A small number of participants suggested that it might be useful to separate beginners from more advanced learners, however all other participants indicated that having one-to-one support ensured that their level of ability was targeted during the course. Some participants indicated that they were initially reluctant to attend the course but through encouragement by their families, and in one case their Speech and Language Therapist, they decided to attend. Although the Orientation seminar was not explicitly discussed by participants, there was a sense that this was essential in putting people at ease in the University environment and obtaining a commitment of attendance from potential participants. Both weekly and more intensive training programmes were considered appropriate course models, however the majority of participants would have preferred the course to be over a longer period of time and many asserted that it should be available for all people with aphasia. Participants valued further opportunities to receive one-to-one support in practising or resolving difficulties around tasks during the Refresher class. Follow-up data indicated a significant fall in computer skills at these classes, notably some considered important in facilitating social engagement, such as reading and replying to emails, and obtaining information from the Internet, therefore raising issues around sustainability of skills without appropriate on-going support.

The inaccessibility of technology and appropriate training continues to be an important issue for people with aphasia limiting their ability to participate equally in society alongside the general population (van de Sandt-Koenderman, 2011; Elman \& Larsen, 2010; Parr, 2007; 
Egan et al, 2004). The third overarching theme from participant discussions described what they considered to be the essential components required by people with aphasia in order to overcome barriers to using technology. Importantly, they highlighted the need for bespoke training over and above that provided by publicly available training courses which included aphasia-accessible materials and fundamentally regular access to one-to-one support. In addition, on-going support by follow-up courses, paid tutors or 'tech-savvy' family/friends was identified as a requirement for resolving post-training computer-related issues.

An essential component of research is the measurement of change from baseline following intervention. The measuring of baseline and progression of computer skills with this participant group in particular, where communication and cognitive impairment may hamper accurate reflection and self-evaluation, is challenging. The tutors in Elman et al's (2004) study used a before and after skills assessment. Participants in this current study self-rated their computer skills prior to and following the training, and at follow-up by those who attended a Refresher class. In addition, SLT students measured the progress of participants' skill and independence during each session; unfortunately the class structure did not accommodate rigorous monitoring of these measures and therefore were not included in this paper. Given the advances in technology, future studies might consider collaborating with Human Computer Interaction specialists in employing technology to record more rigorously objective participant engagement and independence in computer skills as well as highlight specific areas of difficulty.

The findings of this study illustrate how engagement in computer training, given appropriate support, can provide people with aphasia with a sense of achievement, confidence, and independence that can potentially extend beyond the life of the course itself. This sense of 
excitement around the potential use of technology comparable to the general population is beautifully expressed by $\mathrm{CN}$ :

“......it's just been.....terrific...ch- changed.. my life... l;-learning more about ....the internet.... I really want to get the computer up and I want to use it.. I want to be able to use it for me.. just as a- any bloke somewhere you know.. and I never thought I'd be able to do it again." (FG4PC)

\section{Clinical Implications}

Van de Sandt-Koenderman (2011) highlights that the majority of SLT intervention delivers therapy focused on the impairment level of ICF with much less targeting functional and participation levels. Gaining a sense of independence and fostering pleasure or well-being have been highlighted as two of the most frequently mentioned reasons for valuing participation, indicating that clinicians should therefore address participation in the early creation of therapy goals by identifying activities with the client that will have the greatest impact on their independence (Brandenburg et al, 2013). Research indicates that more communication networks, government and healthcare information and services are being provided online therefore people need to be technologically and Internet-savvy if they wish to be able to access these facilities.

Findings from this study certainly indicate that people with aphasia are one group who find it difficult to engage with this technology, supporting Parr's (2011) assertion that access to technology for people with aphasia requires time, expertise and training. Indeed, the essential components of computer training appropriate to the needs of people with aphasia, identified by participants in this study, could argue for the involvement of Speech and Language Therapists in its development, for example, consultation in the design of appropriate 
booklets, provision of training for potential tutors, or actually facilitating the training themselves. Although resource implications present in the development stages, there is clearly a role for supervised SLT students who according to the participants in this study, would make excellent tutors, providing assistance in the adaptation of materials for individual participants, provide 1:1/1:2 support and in turn offer students the opportunity to engage in functional therapy resulting in potentially tangible quality of life changes. While traditionally the training and support of technology is not considered part of the clinician's therapeutic role (Brandenburg, et al., 2013), McCall (2012, p.235) asserts that "it seems clear that successfully using software to empower a person with aphasia to do something that cannot be done without the technology is actually the treatment". Indeed, apart from the potential benefits in terms of improved social interaction and general quality-of-life, computer based software programmes are continually being developed specifically targeting the rehabilitation of aphasia (Ramsberger \& Marie, 2007; Mortley, Wade, Davies, \& Enderby, 2003). Given the present economic climate which has resulted in significant funding and resource cutbacks and therefore reduced availability of face-to-face aphasia rehabilitation (Archibald, Orange \& Jamieson, 2009), Speech and Language Therapists need to consider alternative and flexible means of service delivery, for example, employing the use of technology. However, basic computer skills are an essential precursor to accessing potentially intensive, effective therapy, therefore any ICT illiteracy of this client group and requirements for follow-up support must be targeted if they are to be able to access such rehabilitation. The clinician must therefore consider expanding the range of technology uses in aphasia rehabilitation to span the disorder-orientated, functional treatment and social participation aspects of care (van de Sandt-Koenderman, 2011), although it is acknowledged that clinicians may themselves need training and support in their use of technology in aphasia rehabilitation (Davis \& Copeland, 2006). 


\section{Limitations and Future Directions}

This research developed a bespoke computer course that aimed to narrow the 'digital divide' and target reducing a range of physical, cognitive and communication barriers for a group of people with aphasia. Participants $(n=17)$ were predominantly male, ranged in age $(40: 2-$ 80:11), time post-onset (5 months-12 years), severity and presentation of aphasia (Table 2), experience in using ICT (never to daily use) and were mainly members of self-help groups in the Edinburgh area. It is acknowledged that the small sample pertains to a select group of self-volunteering people who may therefore be motivated to be involved in research and may not represent the aphasia population as a whole. In saying that, the data obtained is invaluable in the information it provides relating to the facilitation of more independent participation in society through ICT and therefore warrants further investigation.

Essentially, this research endeavoured to facilitate the learning of ICT skills with people with a range of aphasia severity and no-one was excluded from the course or opportunity to participate in focus group feedback. Challenges in measuring baseline and progression in ICT skills with this population due to communication and cognitive deficits have been discussed and indicate a need for collaboration with HCI specialists in future research. While experienced facilitators used a range of total communication techniques to ascertain opinions from participants with severe expressive aphasia (some limited to single word and yes/no responses), their aphasia was likely to have limited their participation, for example introducing new ideas for discussion. Therefore, future studies could employ participatory methods considered to be useful in including participant groups who are frequently excluded from the research process (MacFarlane, O’Reilly de-Brún, \& de Brún, 2008), such as the aphasia population. These techniques have been successfully used with people with aphasia and, according to McMenamin, Tierney \& MacFarlane (2015a, p 5), are considered to "promote genuine involvement and participation of participants" (see McMenamin et al, 
2015a; 2015b). Using this methodological approach, participants would be considered coresearchers in the generation, organisation and analysis of data, thus allowing participants with severe aphasia to more fully contribute to the development and evaluation of future ICT projects.

Surplus resources permitted the facilitation of additional focus groups ranging from 5-12 months post-course. These groups provided follow-up information invaluable for designing and sustaining ICT courses. Future research should therefore plan to include follow-up focus groups and ICT skill assessment (e.g. 3, 6 and 12 months post-course) which could more robustly examine the sustainability of newly learned/ relearned skills. As sustainability was an issue for participants in this study who had varying access to post-course ICT support, future research could consider training family members/friends equipping them in supporting long-term use by participants and reducing the need to seek potentially expensive and inaccessible classes/tutors. As technology is now part of everyday life from an early age, basic difficulties such as those experienced by participants in this current study (e.g. turning on/off computer) are likely to lessen. However, given the rapid developments of ICT, without ongoing support, access to new or updated ICT could result in a continued widening of the digital divide for people with aphasia (Elman \& Larsen, 2010).

This study was carried out in a University setting which provided a computer suite that was suitable for the needs of participants in terms of accessibility, canteen facilities and adequate computer technological support. Other venues had been considered for this course but did not provide all the required services. However, the University environment may be off-putting for potential participants and in order to make such vital training available to more participants, future trials could evaluate the provision of ICT skill training in the community setting, for example, libraries or day-centres. It would also be important to engage in 
discussions with SLTs to obtain their views in terms of their potential role in providing this foundational computer training.

\section{Conclusion}

This study provides understanding about the usefulness of technology for people with aphasia through exploring the personal experiences of participants who attended a bespoke computer course. Irrespective of age, severity of aphasia or prior computer experience, all participants highlighted the advantages of using technology in order to facilitate increased communication and an enhanced ability to independently manage their daily lives. Participants considered a number of components to be essential in facilitating their engagement in such courses, in particular, bespoke booklets and fundamentally, one-to-one support from someone who understands how aphasia and other cognitive deficits, impact on their learning. Such 'ramps', or strategies, embedded within the technology environment, will serve to narrow this 'digital divide' through 'support[ing] communicative access and participation regardless of individual capacity' (Law, Bunning, Byng, Farrelly, \& Heyman, 2005; 171). Skills sustainability was clearly an issue with the notable loss of abilities without on-going face-toface support. Findings from this study highlight the need for widely available bespoke computer training with regular appropriate follow-on support to enable people with aphasia engage with computer based technology in a meaningful way. 


\section{REFERENCES}

Akiyama, T. (2009). Using Multimedia Tutorials to Enhance Student Learning of File Management for Adult Beginner Computer Users. Behaviour and Information Technology, 14(2), 107-120.

Archibald, L. M., Orange, J. B., \& Jamieson, D. J. (2009). Implementation of ComputerBased Language Therapy in Aphasia. Therapeutic Advances in Neurological Disorders, 2(5), 299-311.

Berners-Lee, T. (1999). Weaving the Web: The Original Design and Ultimate Destiny of the World Wide Web by its Inventor. San Francisco: Harper.

Bowker, N., \& Tuffin, K. (2002). Disability Discourses for Online Identities. Disability \& Society, 17(3), 327-344.

Bradley, N., \& Poppen, W. (2003). Assistive technology, computers and Internet may decrease sense of isolation for homebound elderly and disabled persons. Technology \& Disability, 15(1), 19-25.

Brandenburg, C., Worrall, L., Rodriguez, A.D. \& Copland, D. (2013). Mobile computing technology and aphasia: An integrated review of accessibility and potential uses, Aphasiology, 27(4), 444-461.

Brown, K., Worrall, L.E., Davidson, B. \& Howe, T. (2012). Living successfully with aphasia: A qualitative meta-analysis of the perspectives of individuals with aphasia, family members, 
and speech-language pathologists. International Journal of Speech-Language Pathology, 14(2), 141-155.

Brumfitt, S. (2006). Psychosocial aspects of aphasia: Speech and language therapists' views on professional practice. Disability \& Rehabilitation, 28(8), 523-534.

Cook, J. A., Fitzgibbon, G., Batteiger, D., Grey, D. D., Caras, S., Dansky, H., \& Priester, F. (2005). Information Technology Attitudes and Behaviours among Individuals with Psychiatric Disabilities Who Use the Internet: Results of a Web-Based Survey. Disability Studies Quarterly, 25, 223-229.

Cooper, J. (2006). The digital divide: the special case of gender. Journal of Computer Assisted Learning, 22(5), 320-334.

Cruice, M., Worrall, L. \& Hickson, L. (2006). Quantifying aphasic people's social lives in the context of non-aphasic peers. Aphasiology, 20, 1210-1225.

Davidson, B., Howe, T., Worrall, L., Hickson, L., \& Togher, L. (2008) Social participation for older people wtih aphasia: The impact of communication disability on friendships. Topics in Stroke Rehabilitation, 15(4), 325-340.

Davis, L., \& Copeland, K. (2006). Computer Use in the Management of Aphasia: A Survey of Practice Patterns and Opinions. Contemporary Issues in Communication Science and Disorders, 33, 138-146. 
Egan, J., Worrall, L., \& Oxenham, D. (2004). Accessible Internet training package helps people with aphasia cross the digital divide. Aphasiology, 18(3), 265-280.

Elman, R. J. (2001). The internet and aphasia: Crossing the digital divide. Aphasiology, 15(10-11), 895-899.

Elman, R. J., \& Larsen, S. (2010, May). Computer and internet use among people with aphasia. Paper presented at the Clinical Aphasiology Conference, Isle of Palms, SC. Retrieved from http://aphasiology.pitt.edu/archive/00002161/

Finch, E. \& Hill, A. J. (2014). Computer use by people with aphasia: A survey investigation. Brain Impairment, 15(2), 107-119.

Gale, N.K., Heath, G., Cameron, E., Rashid, S. \& Redwood, S. (2013). Using the framework method for the analysis of qualitative data in multi-disciplinary health research. $B M C$ Medical Research Methodology, 13, 117.

Grimaldi, C., \& Goette, T. (1999). The Internet and the Independence of Individuals with Disabilities. Internet Research, 9, 272-279.

Grohn, B., Worrall, L., Simmons-Mackie, N. \& Hudson, K. ( 2014). Living successfully with aphasia during the first year post-stroke: a longitudinal qualitative study, Aphasiology, 28:12, $1405-1425$. 
Guo, B. G., Bricout, J. C., \& Huang, J. (2005). A Common Open Space or A Digital Divide? A Social Model Perspective on the Online Disability Community in China. Disability and Society, 20, 49-66.

Hilari, K. (2011). The impact of stroke: Are people with aphasia different to those without? Disability \& Rehabilitation, 33(3), 211-218.

Hilari, K. \& Northcott, S. (2006). Social support in people with chronic aphasia. Aphasiology, 20(1), 17-36.

Kirk, J. and Miller, M.L. (1986) Reliability and Validity in Qualitative Research, London: Sage.

Koss, V., Azad, S., Gurm, A. \& Rosenthal, E. (2013). "This is for Everyone”. The Case for Universal Digitisation. Retrieved 2 May 2015 from: http://www.go-on.co.uk/wpcontent/uploads/2013/12/The-Booz-Report-Nov2012.pdf

Kreuger, R.A. \& Casey, M.A. (2000) Focus Groups: A Practical Guide for Applied Research, 3rd edition. Thousand Oaks, CA: Sage.

Law, J., Huby, G., Irving, A., Pringle, A., Conochie, D., Haworth, C. \& Burston, A. (2010). Reconciling the perspective of practitioner and service user: findings from The Aphasia in Scotland study. International Journal or Language \& Communication Disorders, 45(5), 551560. 
Law, J., Bunning, K., Byng, S., Farrelly, S. \& Heyman, B. (2005). Making sense in primary care: levelling the playing field for people with communication disabilities. Disability and Society, 20, 169-185.

Lazar, R. M., \& Antoniello, D. (2008). Variability in recovery from aphasia. Current Neurology and Neuroscience Reports, 8(6), 497-502.

MacFarlane, A., O’Reilly de-Brún, M. \& de Brún, T. (2008). User involvement: Participatory approach works. BMJ Open, 336, 405-406.

Makin, S. D., Turpin, S., Dennis, M. S., \& Wardlaw, J. M. (2013). Cognitive impairment after lacunar stroke: systematic review and meta-analysis of incidence, prevalence and comparison with other stroke subtypes. Journal of Neurology Neurosurgery Psychiatry, 84(8), 893-900.

McCall. D. (2012). Steps to success with technology for individuals with aphasia. Seminars in Speech and Language. 33, 234-242.

McMenamin, R., Tierney, E. \& MacFarlane, A. (2015a). Addressing the long-term impacts of aphasia: how far does the Conversation Partner Programme go? Aphasiology, DOI: $10.1080 / 02687038.2015 .1004155$

McMenamin, R., Tierney, E. \& MacFarlane, A. (2015b). "Who decides what criteria are important to consider in exploring the outcomes of conversation approaches? A participatory health research study". Aphasiology, DOI: 10.1080/02687038.2015.1006564 
Mok, A., Wong, W., Lam, Y. H., Fan, W. K., Tang, T. K., \& Hui, K. (2004). Cognitive impairment and functional outcome after stroke associated with small vessel disease. Journal of Neurology Neurosurgery Psychiatry, 75, 560-566.

Mortley, J., Wade, J., Davies, A., \& Enderby, P. (2003). An investigation into the feasibility of remotely monitored computer therapy for people with aphasia. Advances in SpeechLanguage Pathology, 3, 27-36.

Nyström, M. (2006). Aphasia - an existential loneliness: A study on the loss of the world of symbols. International Journal of Qualitative Studies on Health and Well-being, 1, 38-49.

Obrenovic, Z., Abascal, J., \& Starcevic, D. (2007). Universal Accessibility as a Multimodal Design Issue. Communications of the ACM, 50(5), 83-88.

Ofcom (2014) International Communications Market Report http://stakeholders.ofcom.org.uk/binaries/research/cmr/cmr14/icmr/ICMR 2014.pdf

Parr, S. (2007). Living with severe aphasia: Tracking social exclusion, Aphasiology, 21(1), 98-123.

Parr, S. (2001). Psychosocial aspects of aphasia: whose perspectives? Folia Phoniatrica et Logopaedica, 53, 266-288.

Pope, C., Ziebland, S. \& Mays, N. (2000). Qualitative research in health care: Analysing qualitative data. $B M J, 320,114-116$. 
Ramsberger, G., \& Marie, B. (2007). Self-administered cued naming therapy: A singleparticipant investigation of a computer-based therapy program replicated in four cases. American Journal of Speech-Language Pathology, 16, 343-358.

Sarno, M. (1993) Aphasia rehabilitation: Psychosocial and ethical considerations. Aphasiology, 17(4); 355-364.

Sarasohn-Kahn, J. (April, 2010) How Smartphones Are Changing Health Care for Consumers and Providers, Think Health, California Healthcare Foundation. Retrieved on 2 May 2015 from: http://www.chcf.org/publications/2010/04/how-smartphones-are-changing-health-carefor-consumers-and-providers\#ixzz3YzmLFTPj

Seymour, W., \& Lupton, D. (2004). Holding the Line Online: Exploring Wired Relationships for People with Disabilities. Disability and Society, 19, 291-305.

Simpson, J. (2009). Inclusive Information and Communication Technologies for People with Disabilities. Disability Studies Quarterly, 29(1), 394-408.

Smith, J., \& Firth, J. (2011) Qualitative data analysis: the framework approach. Nurse Researcher, 18(2), 52-62

Swinburn, K., Porter, G. \& Howard, D. (2004). Comprehensive Aphasia Test. Hove: Psychology Press. 
Van de Sandt-Koenderman, W.M.E. (2011) Aphasia rehabilitation and the role of computer technology: Can we keep up with modern times? International Journal of Speech-Language Pathology, 13(1), 21-27.

Wade, J., Mortley, J. \& Enderby, P. (2003). Talk about IT: Views of people with aphasia and their partners on receiving remotely monitored computer-based word finding therapy. Aphasiology, 17(11), 1031-1056.

W3C (2008). Web Content Accessibility Guidelines 2.0 (WCAG). Retrieved $2^{\text {nd }}$ May 2015 from http://www.w3.org/TR/WCAG20/

Warschauer, M. (2004). Technology and social inclusion: Rethinking the digital divide. Cambridge: MIT Press.

White, H., McConnell, E., Clipp, E., Branch, L. G., Sloane, R., Pieper, C., \& Box, T. L. (2002). A randomized controlled trial of the psychosocial impact of providing Internet training and access to older adults. Aging \& Mental Health, 6, 213-221.

World Health Organization (WHO). (2001). International classification of functioning, disability and health. Geneva.

Zickuhr, K., \& Smith, A. (2012). Digital differences. Computers in Human Behavior, 26 (3), $541-56$ 
Table 1 - Participant communication and computer experience profile (pre and post-stroke, and before and following the computer course) [ordered according to pre-stroke computer experience] $(T P O=$ time post onset; $T$-S Range $=$ Range of $T$-Scores across participants $[$ score of $50=$ mean.;10 from the mean $=1 S D] ;+$ daily $=$ many times daily; $p w=$ times per week $)$

\begin{tabular}{|c|c|c|c|c|c|c|c|c|c|c|c|c|c|c|c|}
\hline & \multirow[t]{4}{*}{$\begin{array}{l}\text { Gender/ } \\
\text { Age }\end{array}$} & \multirow[t]{4}{*}{$\begin{array}{r}\text { TPO } \\
\text { (years) }\end{array}$} & \multicolumn{9}{|c|}{ Comprehensive Aphasia Test Subtest totals and [T-Score] } & \multicolumn{4}{|c|}{$\begin{array}{c}\text { Computer Experience } \\
\text { Times used per week (on average) }\end{array}$} \\
\hline & & & \multirow{3}{*}{$\begin{array}{c}\text { Cognition } \\
\text { [memory] }\end{array}$} & \multicolumn{2}{|c|}{ Comprehension } & \multicolumn{5}{|c|}{ Expression } & \multirow{3}{*}{$\begin{array}{c}\text { Aphasia } \\
\text { Severity } \\
\text { T-S Range } \\
\text { [42-66] }\end{array}$} & \multirow{3}{*}{$\begin{array}{l}\text { Pre- } \\
\text { stroke }\end{array}$} & \multirow{3}{*}{$\begin{array}{l}\text { Post- } \\
\text { stroke }\end{array}$} & \multirow{3}{*}{$\begin{array}{l}\text { Post- } \\
\text { course }\end{array}$} & \multirow{3}{*}{$\begin{array}{c}\text { Refresh } \\
\text { Class } \\
\text { (if attended) }\end{array}$} \\
\hline & & & & Spoken & Written & Naming & Reading & Writing & Picture & escription & & & & & \\
\hline & & & & $\begin{array}{c}\text { T-S Range } \\
{[36-63]}\end{array}$ & $\begin{array}{c}\text { T-S Range } \\
{[43-73]}\end{array}$ & $\begin{array}{c}\text { T-S Range } \\
{[35-70]}\end{array}$ & $\begin{array}{c}\text { T-S Range } \\
{[38-71]}\end{array}$ & $\begin{array}{c}\text { T-S Range } \\
{[44-65]}\end{array}$ & $\begin{array}{c}\text { Spoken } \\
\text { T-S Range } \\
\text { [39-64] }\end{array}$ & $\begin{array}{c}\text { Written } \\
\text { T-S Range } \\
\text { [42-68] }\end{array}$ & & & & & \\
\hline Co & $\mathrm{M} / 71 ; 11$ & 1.3 & $\begin{array}{c}23 / 38 \\
{[34]}\end{array}$ & $\begin{array}{c}35 / 66 \\
{[43]}\end{array}$ & $\begin{array}{c}41 / 62 \\
{[49]}\end{array}$ & $\begin{array}{c}25 \\
{[48]}\end{array}$ & $\begin{array}{c}45 / 70 \\
{[51]}\end{array}$ & $\begin{array}{c}18 / 76 \\
{[44]}\end{array}$ & $\begin{array}{c}1 \\
{[46]}\end{array}$ & $\begin{array}{c}0 \\
{[42]}\end{array}$ & 46 & never & never & $<1 \mathrm{pw}$ & daily \\
\hline GM & $F / 49 ; 4$ & 7 & $\begin{array}{r}27 / 37 \\
{[54]}\end{array}$ & $\begin{array}{l}56 / 66 \\
{[49]}\end{array}$ & $\begin{array}{l}51 / 62 \\
{[57]}\end{array}$ & $\begin{array}{c}45 \\
{[53]}\end{array}$ & $\begin{array}{l}22 / 70 \\
{[50]}\end{array}$ & $\begin{array}{c}45 / 76 \\
{[49]}\end{array}$ & $\begin{array}{c}12 \\
{[49]}\end{array}$ & $\begin{array}{c}3 \\
{[54]}\end{array}$ & 51 & never & never & $1-2 \mathrm{pw}$ & -- \\
\hline HJ & M/63;2 & 3 & $\begin{array}{r}29 / 38 \\
{[43]}\end{array}$ & $\begin{array}{r}61 / 66 \\
{[61]}\end{array}$ & $\begin{array}{r}50 / 62 \\
{[56]}\end{array}$ & $\begin{array}{c}59 \\
{[58]}\end{array}$ & $\begin{array}{l}48 / 70 \\
{[53]}\end{array}$ & $\begin{array}{l}40 / 76 \\
{[49]}\end{array}$ & $\begin{array}{c}24 \\
{[56]}\end{array}$ & $\begin{array}{c}9 \\
957]\end{array}$ & 57 & never & never & $<1 \mathrm{pw}$ & -- \\
\hline BH & $\mathrm{M} / 71 ; 2$ & 6.5 & $\begin{array}{c}31 / 38 \\
{[54]}\end{array}$ & $\begin{array}{c}5 / 66 \\
{[48]}\end{array}$ & $\begin{array}{c}45 / 62 \\
{[52]}\end{array}$ & $\begin{array}{c}54 \\
{[55]}\end{array}$ & $\begin{array}{c}57 / 70 \\
{[57]}\end{array}$ & $\begin{array}{c}53 / 76 \\
{[51]}\end{array}$ & $\begin{array}{c}38 \\
{[62]}\end{array}$ & $\begin{array}{c}10 \\
{[58]}\end{array}$ & 55 & $<1 \mathrm{pw}$ & $<1 \mathrm{pw}$ & $1-2 \mathrm{pw}$ & $1-2 \mathrm{pw}$ \\
\hline DR & F/74;11 & 5 & $\begin{array}{r}32 / 38 \\
{[47]}\end{array}$ & $\begin{array}{r}63 / 66 \\
{[63]}\end{array}$ & $\begin{array}{r}62 / 62 \\
{[73]}\end{array}$ & $\begin{array}{c}81 \\
{[69]}\end{array}$ & $\begin{array}{r}68 / 70 \\
{[66]}\end{array}$ & $\begin{array}{l}75 / 76 \\
{[65]}\end{array}$ & $\begin{array}{c}40 \\
{[63]}\end{array}$ & $\begin{array}{c}19 \\
{[66]}\end{array}$ & 66 & $<1 \mathrm{pw}$ & $<1 \mathrm{pw}$ & $3-5 \mathrm{pw}$ & 3-5 pw \\
\hline HE & M/69;10 & 6 & $\begin{array}{c}29 / 38 \\
{[50]}\end{array}$ & $\begin{array}{c}24 / 66 \\
{[36]}\end{array}$ & $\begin{array}{c}27 / 62 \\
{[43]}\end{array}$ & $\begin{array}{c}12 \\
\text { [45] }\end{array}$ & $\begin{array}{l}0 / 70 \\
{[38]}\end{array}$ & $\begin{array}{c}26 / 76 \\
{[45]}\end{array}$ & $\begin{array}{c}0 \\
{[39]}\end{array}$ & $\begin{array}{c}0 \\
{[42]}\end{array}$ & 42 & $1-2 \mathrm{pw}$ & never & $3-5 \mathrm{pw}$ & -- \\
\hline
\end{tabular}




\begin{tabular}{|c|c|c|c|c|c|c|c|c|c|c|c|c|c|c|c|}
\hline QN & M/68;10 & 3 & $\begin{array}{c}35 / 38 \\
{[62]}\end{array}$ & $\begin{array}{c}59 / 66 \\
{[59]}\end{array}$ & $\begin{array}{c}54 / 62 \\
{[60]}\end{array}$ & $\begin{array}{c}66 \\
{[61]}\end{array}$ & $\begin{array}{r}60 / 70 \\
{[59]}\end{array}$ & $\begin{array}{c}67 / 76 \\
{[57]}\end{array}$ & $\begin{array}{c}43 \\
{[64]}\end{array}$ & $\begin{array}{c}24 \\
{[68]}\end{array}$ & 61 & $1-2 \mathrm{pw}$ & daily & daily & + daily \\
\hline QI & $\mathrm{M} / 67 ; 10$ & $\begin{array}{l}\text { non- } \\
\text { stroke }\end{array}$ & $\begin{array}{l}37 / 38 \\
{[54]}\end{array}$ & $\begin{array}{c}60 / 66 \\
{[60]}\end{array}$ & $\begin{array}{c}59 / 62 \\
{[66]}\end{array}$ & $\begin{array}{c}76 \\
{[66]}\end{array}$ & $\begin{array}{l}69 / 70 \\
{[67]}\end{array}$ & $\begin{array}{c}\text { 73/76 } \\
{[62]}\end{array}$ & $\begin{array}{c}34 \\
{[60]}\end{array}$ & $\begin{array}{c}18 \\
{[65]}\end{array}$ & 65 & $1-2 \mathrm{pw}$ & never & $1-2 \mathrm{pw}$ & daily \\
\hline CX & M68;11 & 5 & $\begin{array}{c}36 / 38 \\
{[54]}\end{array}$ & $\begin{array}{l}58 / 66 \\
{[58]}\end{array}$ & $\begin{array}{l}55 / 62 \\
{[52]}\end{array}$ & $\begin{array}{c}77 \\
{[67]}\end{array}$ & $\begin{array}{l}70 / 70 \\
{[71]}\end{array}$ & $\begin{array}{c}\text { 70/76 } \\
{[59]}\end{array}$ & $\begin{array}{c}40 \\
{[63]}\end{array}$ & $\begin{array}{c}23 \\
{[68]}\end{array}$ & 63 & $3-5 \mathrm{pw}$ & never & daily & daily \\
\hline UT & M/80;11 & 3 & $\begin{array}{c}36 / 38 \\
{[54]}\end{array}$ & $\begin{array}{c}59 / 66 \\
{[59]}\end{array}$ & $\begin{array}{l}51 / 62 \\
{[57]}\end{array}$ & $\begin{array}{c}44 \\
{[53]}\end{array}$ & $\begin{array}{r}68 / 70 \\
{[66]}\end{array}$ & $\begin{array}{c}64 / 76 \\
{[56]}\end{array}$ & $\begin{array}{l}32.5 \\
{[60]}\end{array}$ & $\begin{array}{l}22 \\
{[67]}\end{array}$ & 59 & $3-5 \mathrm{pw}$ & $<1 \mathrm{pw}$ & $3-5 \mathrm{pw}$ & never $^{1}$ \\
\hline $\mathrm{CN}$ & M/59;3 & 12 & $\begin{array}{l}32 / 38 \\
{[47]}\end{array}$ & $\begin{array}{c}33.5 / 66 \\
{[42]}\end{array}$ & $\begin{array}{c}47 / 62 \\
{[53]}\end{array}$ & $\begin{array}{c}52 \\
{[55]}\end{array}$ & $\begin{array}{r}54 / 70 \\
{[56]}\end{array}$ & $\begin{array}{c}38 / 76 \\
{[48]}\end{array}$ & $\begin{array}{c}35 \\
{[61]}\end{array}$ & $\begin{array}{c}5 \\
{[55]}\end{array}$ & 52 & daily & never & daily & -- \\
\hline KN & M/64;7 & 2 & $\begin{array}{c}32 / 38 \\
{[47]}\end{array}$ & $\begin{array}{c}57 / 66 \\
{[57]}\end{array}$ & $\begin{array}{r}56 / 60 \\
{[65]}\end{array}$ & $\begin{array}{c}63 \\
{[59]}\end{array}$ & $\begin{array}{r}65 / 70 \\
{[63]}\end{array}$ & $\begin{array}{c}65 / 76 \\
{[57]}\end{array}$ & $\begin{array}{c}25 \\
{[56]}\end{array}$ & $\begin{array}{c}6 \\
{[55]}\end{array}$ & 60 & daily & daily & daily & $3-5 \mathrm{pw}$ \\
\hline TH & F/70;2 & 0.9 & $\begin{array}{c}32 / 38 \\
{[54]}\end{array}$ & $\begin{array}{c}58 / 66 \\
{[58]}\end{array}$ & $\begin{array}{c}54 / 62 \\
{[60]}\end{array}$ & $\begin{array}{c}64 \\
{[60]}\end{array}$ & $\begin{array}{r}66 / 70 \\
{[64]}\end{array}$ & $\begin{array}{c}67 / 76 \\
{[57]}\end{array}$ & $\begin{array}{c}21 \\
{[53]}\end{array}$ & $\begin{array}{c}5 \\
{[55]}\end{array}$ & 58 & daily & never & $1-2 \mathrm{pw}$ & daily \\
\hline TN & M/54;3 & 1 & $\begin{array}{c}33 / 38 \\
{[62]}\end{array}$ & $\begin{array}{c}63 / 66 \\
{[63]}\end{array}$ & $\begin{array}{c}54 / 62 \\
{[60]}\end{array}$ & $\begin{array}{c}84 \\
{[70]}\end{array}$ & $\begin{array}{c}62 / 70 \\
{[59]}\end{array}$ & $\begin{array}{r}63 / 76 \\
{[55]}\end{array}$ & $\begin{array}{c}19 \\
{[53]}\end{array}$ & $\begin{array}{c}21 \\
{[66]}\end{array}$ & 61 & daily & daily & +daily & daily \\
\hline TP & $\mathrm{M} / \mathbf{4 0 ; 2}$ & 11 & $\begin{array}{l}37 / 38 \\
{[62]}\end{array}$ & $\begin{array}{r}53 / 66 \\
{[53]}\end{array}$ & $\begin{array}{c}51 / 62 \\
{[57]}\end{array}$ & $\begin{array}{c}42 \\
{[52]}\end{array}$ & $\begin{array}{r}22 / 70 \\
{[47]}\end{array}$ & $\begin{array}{c}56 / 76 \\
{[52]}\end{array}$ & $\begin{array}{c}14 \\
{[50]}\end{array}$ & $\begin{array}{c}9 \\
{[57]}\end{array}$ & 52 & +daily & daily & +daily & -- \\
\hline EI & M/43;11 & $11+1.5$ & $\begin{array}{c}37 / 38 \\
{[62]}\end{array}$ & $\begin{array}{r}46 / 66 \\
{[49]}\end{array}$ & $\begin{array}{r}50 / 62 \\
{[56]}\end{array}$ & $\begin{array}{c}47 \\
{[54]}\end{array}$ & $\begin{array}{r}28 / 70 \\
{[47]}\end{array}$ & $\begin{array}{r}46 / 76 \\
{[50]}\end{array}$ & $\begin{array}{c}19 \\
{[53]}\end{array}$ & $\begin{array}{c}8 \\
{[57]}\end{array}$ & 51 & +daily & +daily & +daily & -- \\
\hline BT & M/61;2 & 0.5 & $\begin{array}{c}33 / 38 \\
{[54]}\end{array}$ & $\begin{array}{c}46 / 66 \\
{[49]}\end{array}$ & $\begin{array}{c}48 / 62 \\
{[54]}\end{array}$ & $\begin{array}{c}0 \\
{[35]}\end{array}$ & $\begin{array}{l}1 / 70 \\
{[40]}\end{array}$ & $\begin{array}{c}48 / 76 \\
{[50]}\end{array}$ & $\begin{array}{c}6 \\
\text { [47] }\end{array}$ & $\begin{array}{c}0 \\
{[42]}\end{array}$ & 45 & +daily & never & $3-5 \mathrm{pw}$ & -- \\
\hline
\end{tabular}


Table 2 - Class content - these skills were taught using a range of methods to facilitate learning e.g. PowerPoint presentation at top of class with examples, followed by exercises with bespoke booklets and 1:1 or 2:1 support in addition to home practice tasks, for example, sending and responding to emails.

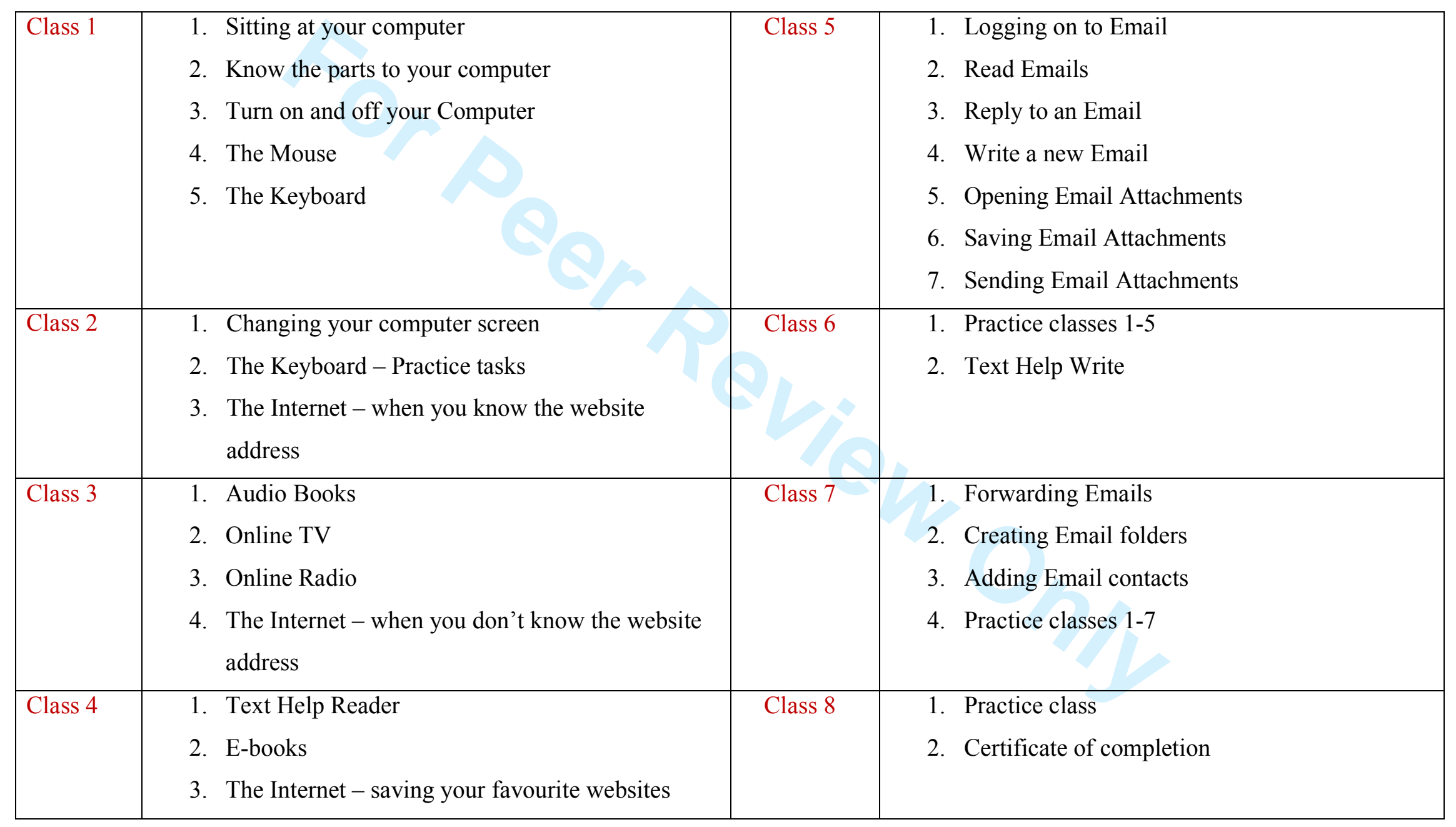


Table 3 - Comparison of percentage in self-rating abilities prior to and following the computer course $(n=16)$

\begin{tabular}{|c|c|c|c|c|c|c|c|}
\hline & & \multicolumn{2}{|c|}{ No problem-OK } & \multicolumn{2}{|c|}{ Slightly difficult-Difficult } & \multicolumn{2}{|c|}{ Very difficult-Impossible } \\
\hline & $\begin{array}{c}\text { Wilcoxon Signed } \\
\text { Ranks Test }\end{array}$ & $\begin{array}{c}\text { Pre-course } \\
\%-n=16\end{array}$ & $\begin{array}{c}\text { Post-course } \\
\%-n=16\end{array}$ & $\begin{array}{c}\text { Pre- course } \\
\%-n=16\end{array}$ & $\begin{array}{c}\text { Post-course } \\
\%-n=16\end{array}$ & $\begin{array}{c}\text { Pre-course } \\
\%-n=16\end{array}$ & $\begin{array}{c}\text { Post-course } \\
\%-n=16\end{array}$ \\
\hline Turn computer on and off & $\mathrm{z}=-2.539, \mathrm{p}<0.05$ & 50 & 88 & 19 & 12 & 31 & $\mathbf{0}$ \\
\hline Connect to Internet & $z=-2.699, p<0.01$ & 38 & 81 & 12 & 19 & 50 & $\mathbf{0}$ \\
\hline Go to a Website & $\mathrm{z}=-2.762, \mathrm{p}<0.01$ & 19 & 62 & 44 & 38 & 37 & $\mathbf{0}$ \\
\hline Information from Internet & $\mathrm{z}=-3.344, \mathrm{p}<0.01$ & 12 & 75 & 25 & 25 & 63 & $\mathbf{0}$ \\
\hline Use 'Favourites' & $z=-2.454, p<0.05$ & 25 & 50 & 19 & 44 & 56 & 6 \\
\hline Connect to email & $z=-2.689, p<0.01$ & 38 & 81 & 12 & 19 & 50 & $\mathbf{0}$ \\
\hline Read email & $\mathrm{z}=-2.223, \mathrm{p}<0.05$ & 44 & 81 & 19 & 19 & 37 & $\mathbf{0}$ \\
\hline Reply to emails & $\mathrm{z}=-2.594, \mathrm{p}<0.01$ & 31 & 63 & 13 & 37 & 56 & $\mathbf{0}$ \\
\hline Print a page & $\mathrm{z}=-.141, \mathrm{p}=.888$ & 38 & 38 & 6 & 19 & 56 & 44 \\
\hline Use online social media & $\mathrm{z}=-.918, \mathrm{p}=.359$ & 6 & 13 & 0 & 12 & 88 & 75 \\
\hline
\end{tabular}


Table 4 - Comparison of percentage in self-rating abilities following the computer course and refresher course $(n=10)$

\begin{tabular}{|c|c|c|c|c|c|c|c|c|}
\hline & & \multicolumn{2}{|c|}{ No problem-OK } & \multicolumn{2}{|c|}{ Slightly difficult-Difficult } & \multicolumn{2}{|c|}{ Very difficult-Impossible } & \multirow{2}{*}{$\begin{array}{l}\text { Don't us } \\
\text { Refreshe } \\
\%-n=10\end{array}$} \\
\hline & $\begin{array}{l}\text { Wilcoxon Signed } \\
\text { Ranks Test }\end{array}$ & $\begin{array}{c}\text { Post-course } \\
\%-n=10\end{array}$ & $\begin{array}{c}\text { Refresher } \\
\%-n=10\end{array}$ & $\begin{array}{c}\text { Post-course } \\
\%-n=10\end{array}$ & $\begin{array}{c}\text { Refresher } \\
\%-n=10\end{array}$ & $\begin{array}{c}\text { Post-course } \\
\%-n=10\end{array}$ & $\begin{array}{l}\text { Refresher } \\
\%-n=10\end{array}$ & \\
\hline Turn computer on and off & $\mathrm{z}=-.828, \mathrm{p}=.408$ & 90 & 90 & 10 & 10 & 0 & $\mathbf{0}$ & $\mathbf{0}$ \\
\hline Connect to Internet & $\mathrm{z}=-1.414, \mathrm{p}=.157$ & 90 & 90 & 10 & $\mathbf{0}$ & 0 & $\mathbf{0}$ & 10 \\
\hline Go to a Website & $\mathrm{z}=-.680, \mathrm{p}=.496$ & 70 & 70 & 30 & 10 & 0 & 10 & 10 \\
\hline Information from Internet & $\mathrm{z}=-2.043, \mathrm{p}<0.05$ & 80 & 40 & 20 & 20 & 0 & 30 & 10 \\
\hline Use 'Favourites' & $\mathrm{z}=-2.328, \mathrm{p}<0.05$ & 40 & 30 & 60 & 20 & 0 & 10 & 40 \\
\hline Read email & $\mathrm{z}=-1.913, \mathrm{p}=.056$ & 90 & 60 & 10 & 30 & 0 & 10 & $\mathbf{0}$ \\
\hline Reply to emails & $\mathrm{z}=-2.041, \mathrm{p}<0.05$ & 70 & 50 & 30 & 30 & 0 & 20 & $\mathbf{0}$ \\
\hline Print a page & $\mathrm{z}=-.408, \mathrm{p}=.683$ & 50 & 70 & 10 & $\mathbf{0}$ & 0 & 10 & 20 \\
\hline Use online social media & $\mathrm{z}=-.447, \mathrm{p}=.655$ & 10 & 10 & 20 & 10 & 0 & 10 & 70 \\
\hline
\end{tabular}


Figure 1 - Flow of participation in study (attendance was 100\% unless indicated)

Flow of participation in study $218 \times 240 \mathrm{~mm}(96 \times 96$ DPI $)$ 


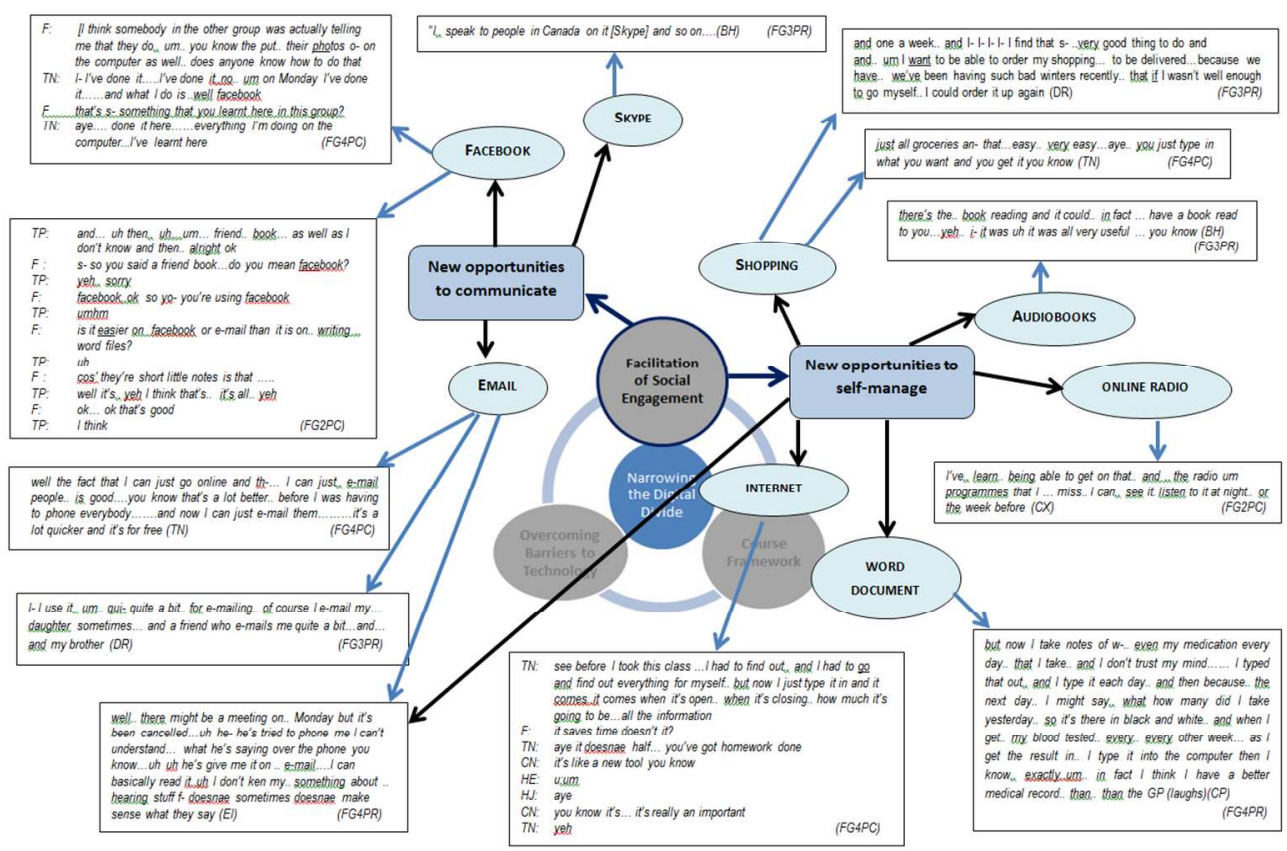

Visual Representation of Framework - facilitation of social engagement $\mathrm{F}=$ facilitator, other pseudonyms = participants; FG identifies focus group origin; PC=post-course; PR=postrefresher class. $352 \times 232 \mathrm{~mm}(96 \times 96$ DPI $)$ 


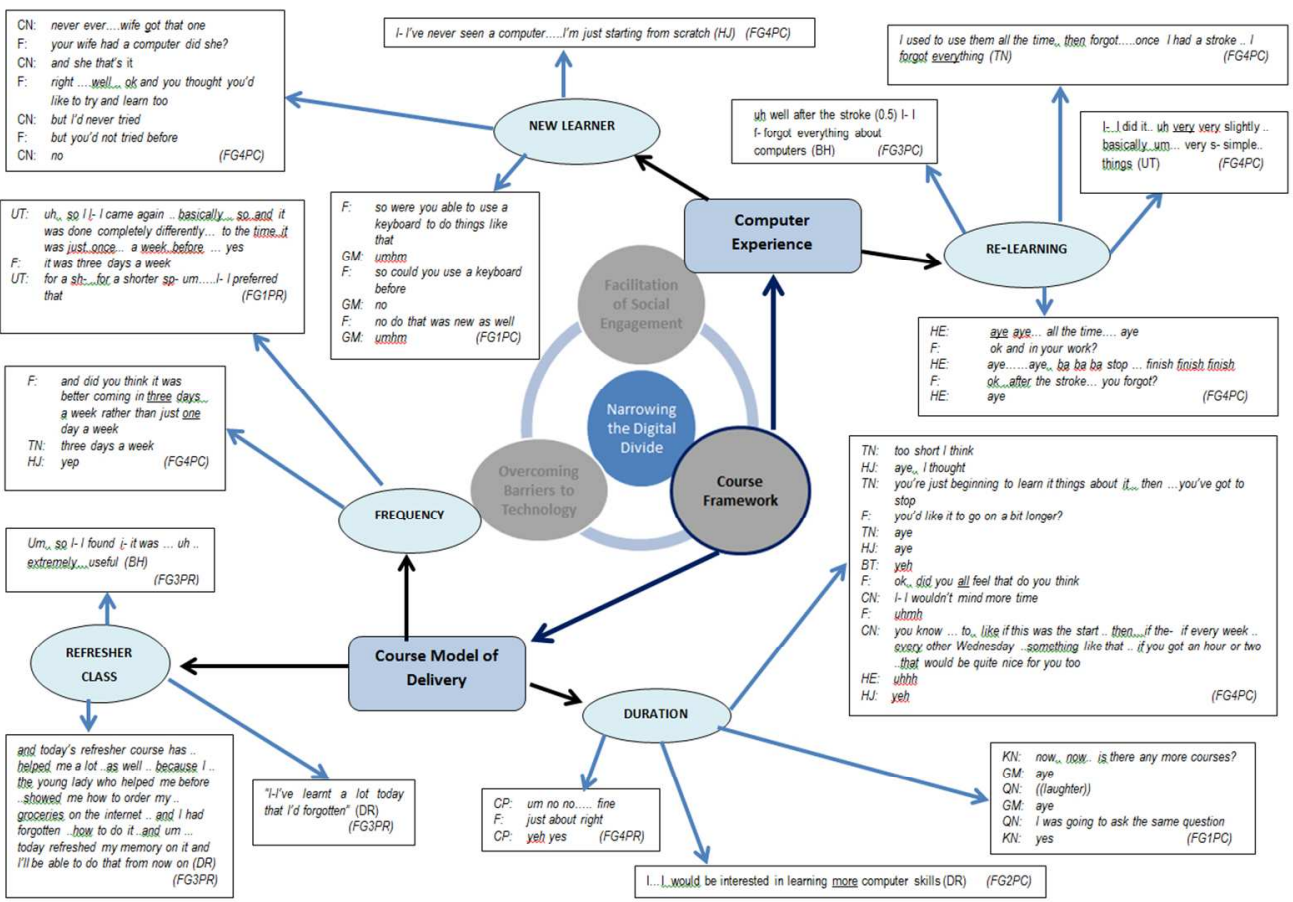

Visual Representation of Framework - course framework $\mathrm{F}=$ facilitator, other pseudonyms = participants; FG identifies focus group origin; $P C=$ post-course; PR=postrefresher class. $348 \times 241 \mathrm{~mm}(96 \times 96$ DPI $)$ 


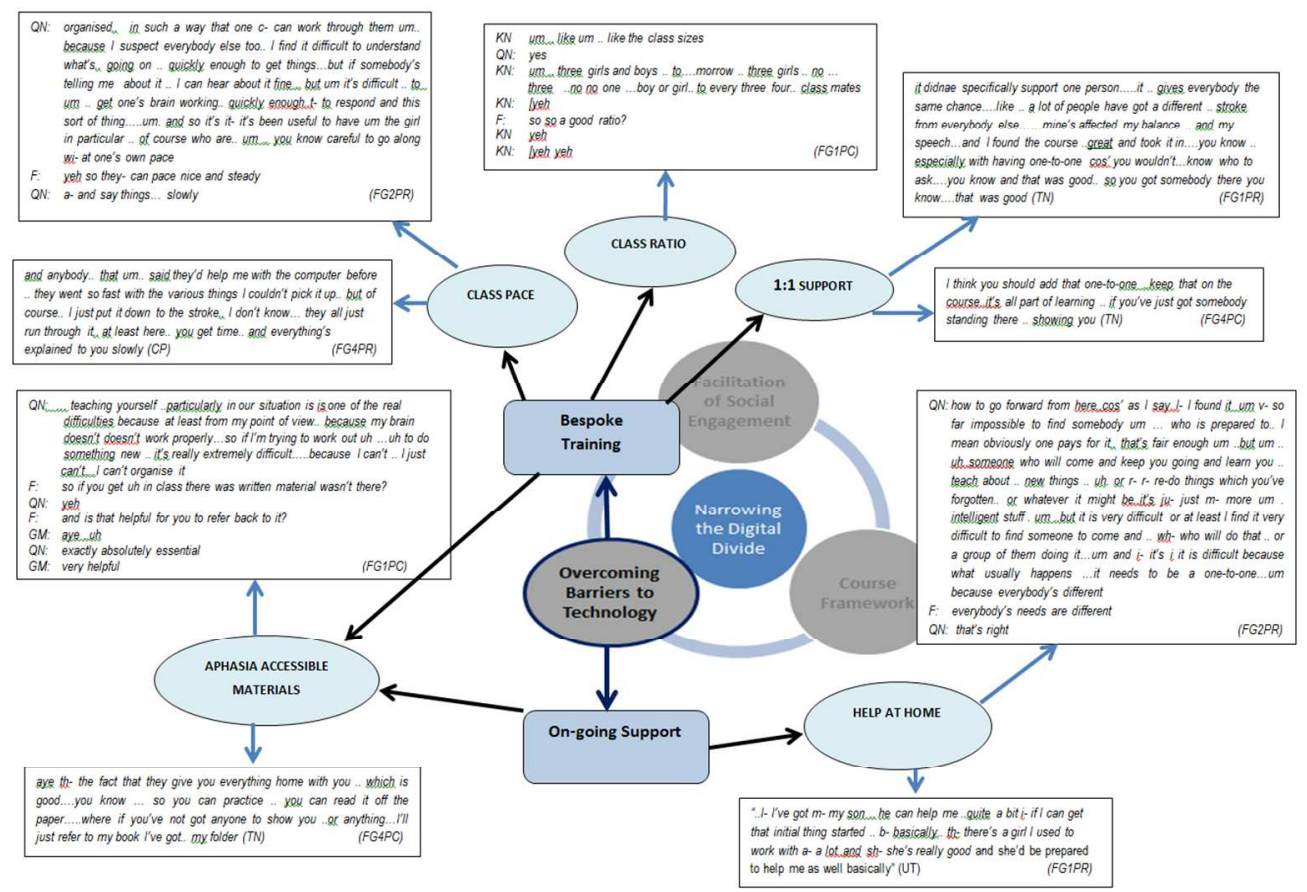

Visual Representation of Framework - overcoming barriers to technology $\mathrm{F}=$ facilitator, other pseudonyms = participants; FG identifies focus group origin; $P C=$ post-course; $P R=$ postrefresher class.

$351 \times 241 \mathrm{~mm}$ (96 x 96 DPI) 
Appendix

Topic Guide - Focus Groups

\begin{tabular}{|c|c|c|}
\hline & Post-Course Focus Groups & Refresher Class Focus Groups \\
\hline & $\begin{array}{l}\text { Key Objectives: } \\
\text { - Establishing prior experience of ICT } \\
\text { before their stroke and before classes } \\
\text { - } \\
\text { Establishing individual experiences of the } \\
\text { course } \\
\text { - Establishing how individuals envisage } \\
\text { future computer use } \\
\text { - Establish how ICT can help them with } \\
\text { post-stroke communication difficulties }\end{array}$ & $\begin{array}{l}\text { Key Objectives: } \\
\text { - Establishing individual experiences of the } \\
\text { course (to include those few participants } \\
\text { who did not attend immediate post-course } \\
\text { focus groups) } \\
\text { - } \\
\text { Establishing ICT use and change since the } \\
\text { course } \\
\text { - Establishing impact in everyday lives } \\
\text { - Establish usefulness of Refresher Class } \\
\text { Establish how ICT can help them with } \\
\text { post-stroke communication difficulties }\end{array}$ \\
\hline 1. & $\begin{array}{l}\text { troductions } \\
\text { - Purpose of discussion } \\
\text { - } \quad \text { Explain emphasis on ICT rather than their br } \\
\text { - }\end{array}$ & iences of stroke \\
\hline 2. & $\begin{array}{l}\text { ICT use before their stroke and before the classes } \\
\text { PROBE: distinguish between ICT high users/very } \\
\text { experienced before stroke (i.e. relearning lost } \\
\text { knowledge) and ICT inexperienced (learning for } \\
\text { first time) }\end{array}$ & $\begin{array}{l}\text { Relate their experiences of the course } \\
\text { PROBE: what wanted to learn; what achieved; did } \\
\text { it meet expectations; what helped most; method of } \\
\text { delivery (talk, student mentoring etc); length of } \\
\text { course, usefullirrelevant; focus on contact with } \\
\text { people e.g. grandchildren, relatives abroad, } \\
\text { shopping rather than keyboard use etc. }\end{array}$ \\
\hline 3. & $\begin{array}{l}\text { Relate their experiences of the course } \\
\text { PROBE: what wanted to learn; what achieved; did } \\
\text { it meet expectations; what helped most; method of } \\
\text { delivery (talk, student mentoring etc); length of } \\
\text { course, usefullirrelevant; focus on contact with } \\
\text { people e.g. grandchildren, relatives abroad, } \\
\text { shopping rather than keyboard use etc. }\end{array}$ & $\begin{array}{l}\text { How much have they used ICT at home since the } \\
\text { course? Is it different than before the course } \\
\text { PROBE: distinguish between ICT high users/very } \\
\text { experienced before stroke (i.e. relearning lost } \\
\text { knowledge) and ICT inexperienced (learning for } \\
\text { first time) and changes since the course }\end{array}$ \\
\hline 4. & $\begin{array}{l}\text { Relate how they are expecting to use computers in } \\
\text { the future } \\
\text { PROBE: link to what they said originally and their } \\
\text { expectations; do they need additional help and are } \\
\text { there people there to provide it (spouses/children } \\
\text { etc); optimism future computer use and what for, } \\
\text { e.g. connectivity and networking using computers - } \\
\text { can it reduce experience of isolation felt by many? }\end{array}$ & $\begin{array}{l}\text { What are they using the computer for since the } \\
\text { course } \\
\text { PROBE: functional use i.e. using for things like } \\
\text { Facebook or emails to keep in touch with people; } \\
\text { finding out information on the Internet; online } \\
\text { shopping etc. what impact is this making on their } \\
\text { lives? }\end{array}$ \\
\hline 5. & $\begin{array}{l}\text { More general discussion about how much } \\
\text { computers can help them cope with difficulties they } \\
\text { experience following stroke } \\
\text { PROBE: needs of people with aphasia; potential } \\
\text { for ICT training to help people re-establish } \\
\text { networks; get back into employment; take control of } \\
\text { their lives or do they think computers are mainly } \\
\text { for entertainment (e.g. films). How should such } \\
\text { training be offered? Is this a question of SLT due to } \\
\text { communication needs? Should we be developing the } \\
\text { course further and looking for funding or should a }\end{array}$ & $\begin{array}{l}\text { Usefulness of Refresher Class } \\
\text { PROBE: how has this helped e.g. more practice, } \\
\text { help remember things forgotten, enjoyed meeting } \\
\text { people again/new people etc. ask for specifics \& } \\
\text { examples. Briefly probe how important the } \\
\text { lunchtime break was in getting the opportunity to } \\
\text { chat with other people who have aphasia }\end{array}$ \\
\hline
\end{tabular}




\begin{tabular}{|c|c|c|}
\hline & wider range of people offer this locally? & \\
\hline 6. & & $\begin{array}{l}\text { Relate how they are expecting to use computers in } \\
\text { the future } \\
\text { PROBE: link to what they said originally and their } \\
\text { expectations; do they need additional help and are } \\
\text { there people there to provide it (spouses/children } \\
\text { etc); optimism future computer use and what for, } \\
\text { e.g. connectivity and networking using computers - } \\
\text { can it reduce experience of isolation felt by many? }\end{array}$ \\
\hline 7. & & $\begin{array}{l}\text { More general discussion about how much computers } \\
\text { can help them cope with difficulties they experience } \\
\text { following stroke } \\
\text { PROBE: needs of people with aphasia; potential for } \\
\text { ICT training to help people re-establish networks; } \\
\text { get back into employment; take control of their lives } \\
\text { or do they think computers are mainly for } \\
\text { entertainment (e.g. films). How should such training } \\
\text { be offered? Is this a question of SLT due to } \\
\text { communication needs? Should we be developing the } \\
\text { course further and looking for funding or should a } \\
\text { wider range of people offer this locally? }\end{array}$ \\
\hline
\end{tabular}

